Daiana Sganzella

\title{
ULTRA-SOM PULSADO DE BAIXA INTENSIDADE NA REGENERAÇÃO NERVOSA PERIFÉRICA DE RATOS
}

\author{
Dissertação apresentada ao Programa de Pós-Graduação \\ Interunidades em Bioengenharia - Escola de Engenharia de \\ São Carlos / Faculdade de Medicina Ribeirão Preto / \\ Instituto de Química de São Carlos, da Universidade de São \\ Paulo, como parte dos requisitos para a obtenção do título \\ de mestre em Bioengenharia.
}

Orientador: Prof. Dr. João Manuel Domingos de Almeida Rollo

São Carlos

2007 
Dedico este trabalho a DEUS, pois sem ELE, nada teria conseguido. A minha família pais, irmão, esposo e especialmente ao mais novo integrante, meu filho, João Marcelo. 


\section{AGRADECIMENTOS}

Meu agradecimento especial aos meus pais, Odair e Shirlei, exemplo de vida e amor incondicional, vocês foram, são e serão fundamentais em minha vida, amo muito vocês.

Ao meu esposo, Raniery, que sempre me apoiou e compreendeu todos os momentos ao meu lado.

Ao meu filhinho, João Marcelo, que é tudo na minha vida, o melhor presente que ganhei.

Aos meus companheiros de trabalho árduo: Davilene e Thiago, sem a ajuda de vocês, não sei o que teria sido de mim. Obrigada por toda a ajuda durante estes quase 2 anos, muita sorte a vocês, pois merecem muito.

Ao meu orientador professor Dr. João Rollo, pela oportunidade, compreensão com o trabalho e pelos ensinamentos.

Ao professor Dr. Nivaldo Parizotto por ter aberto as portas de seu laboratório com tanta presteza e ajuda nos momentos difíceis.

As amigas: Vanyzia (Vá), Olívia, Andréa, Luciana, Andréia, Nelina, saudades de todas vocês. E a mais nova de todas Fernanda (Fer), muito obrigada pelas correções até de madrugada.

A secretária da Bioengenharia Janete, a Bárbara pela atenção disponível sempre e aos técnicos Nelson e Mário pela ajuda quando fosse possível. 
"A mente que se abre a novas idéias jamais volta a seu tamanho original." (Albert Einstein) 


\section{Resumo}

Sganzella, D. (2007). Ultra-som pulsado de baixa intensidade na regeneração nervosa periférica de ratos.64p. Programa de Pós-Graduação Interunidades em BioengenhariaEESC/FMRP/IQSC da Universidade de São Paulo, São Carlos, 2007.

O ultra-som é uma das formas de tratamento terapêutico, não-invasivo, que pode auxiliar na regeneração nervosa periférica. Dentre todas estas técnicas não-invasivas de regeneração nervosa periférica, pouco se sabe sobre a influência do ultra-som na regeneração desse tecido. Para tanto foi realizado um trabalho experimental com o objetivo de avaliar o efeito da terapia do ultra-som pulsado de baixa intensidade após lesão por esmagamento do nervo ciático de rato. Foram utilizados 26 ratos Wistar machos, com massa corporal média de 289,61g divididos em 3 grupos: normal (N), lesado (L) e lesado+ ultra-som (L+US). A aplicação do ultra-som pulsado $\left(1 \mathrm{MHz}, 40 \mathrm{~mW} / \mathrm{cm}^{2}, 8\right.$ minutos de duração) iniciou-se 1 dia pós-lesão e repetido por 4 semanas em dias alternados. A análise funcional do nervo ciático (análise de marcha em pista) foi avaliada semanalmente durante todo o período experimental. Para verificar a eficácia do ultra-som sobre a regeneração nervosa foram analisados índice funcional do ciático, morfologia do nervo ciático e morfologia e morfometria muscular dos músculos tibial anterior (TA) e sóleo (SOL). Concluiu-se que o tratamento com o ultra-som pulsado de baixa intensidade na regeneração nervosa periférica não obteve resultados significativos quando se comparou os grupos lesado e lesado+ultra-som, apenas foi observada uma manutenção da área de secção transversa do grupo lesado+ultra-som do músculo TA quando comparado ao grupo normal, levando a indícios de que o ultra-som estimulou o nervo para tal manutenção. 
Palavras-chave: ultra-som pulsado de baixa intensidade; regeneração nervosa periférica; músculo desnervado, índice funcional do ciático, esmagamento.

\begin{abstract}
Sganzella, D. (2007). Effect low-intensity pulsed ultrasound in peripheral nerve regeneration of the rats. 64p. Programa de Pós-Graduação Interunidades em BioengenhariaEESC/FMRP/IQSC da Universidade de São Paulo, São Carlos, 2007.

The ultrasound is one of the forms therapeutic treatment, no-invasive, that it assists in regeneration peripheral nerve. For in such a way an experimental work was carried through with the objective to verify the effect of the therapy of low intensity pulsed ultrasound after crush of sciatic nerve. Twenty six male Wistar rats weighing $289,61 \mathrm{~g}$ on average were used and divided into three groups: normal $(\mathrm{N})$, injury (L) and injury+ultrasound (L+US). The application of the pulsed ultrasound ( $1 \mathrm{Mhz}, 40 \mathrm{~mW} / \mathrm{cm}^{2}$ and 8 minutes duration) was started one day after lesion and repeated for 4 week in alternate day. The functional analysis of the sciatic nerve (analysis of the march in track) was evaluated at weekly during all the experimental period. To verify the effectiveness of the ultrasound on nerve regeneration they had been analyzed sciatic functional index, morphology of the sciatic nerve and muscle morphology and morfometry of the muscles tibial anterior (TA) and sóleo (SOL). It was concluded that the treatment with the device of ultrasound of low intensity in regeneration peripheral nerve did not get resulted significant when compared the groups injured and injury+ultrasound, was only observed a maintenance of the cross-sectional area of the group injury+ultrasound of the muscle TA when compared with the normal group, taking the indications of that the ultrasound stimulated the nerve for such maintenance.
\end{abstract}


Key words: low intensity ultrasound; regeneration peripheral nerve; denervated muscle; sciatic functional index, crush.

\section{LISTA DE FIGURAS}

Figura 1. - Roteiro Simplificado do procedimento experimental realizado.

Figura 2A - Pinça utilizada para o procedimento de esmagamento do nervo ciático 30

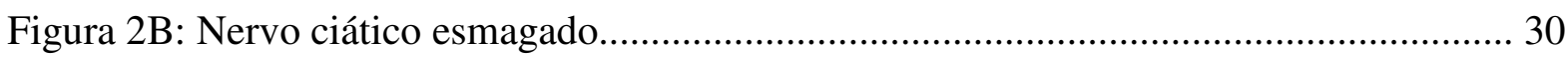

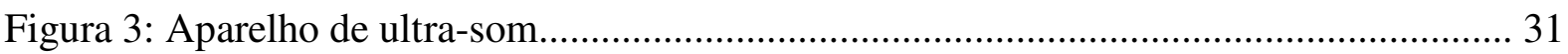

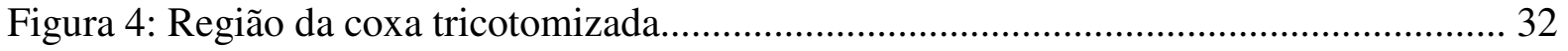

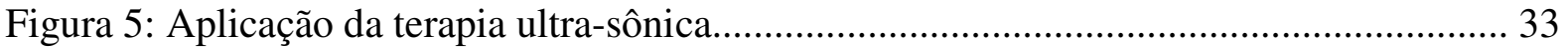

Figura 6 A: Procedimento realizado para a impregnação das patas dos ratos........................ 35

Figura 6 B: Vista das pegadas dos animais caminhando pela passarela............................... 35

Figura 7: Fotomicrografia de cortes histológicos de secção transversal dos músculos tibial anterior (TA) e sóleo (SOL)

Figura 8: Área de secção transversa (AST) das fibras musculares dos músculos tibial anterior (TA) e sóleo (SOL)

Figura 9: Fotomicrografia de corte transversal do nervo ciático. 42

Figura 10: Índice funcional do ciático. 


\section{LISTA DE TABELAS}

Tabela 1 - Pesquisa sobre o efeito do ultra-som pulsado de baixa intensidade, em diferentes freqüências, intensidades e tempo de tratamento em lesão nervosa periférica e seus

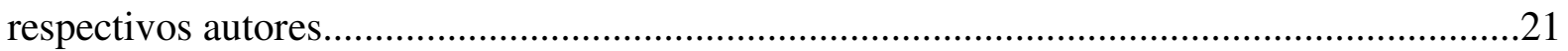

Tabela 2: Massa corporal e dos músculos tibial anterior (TA) e sóleo (SOL) 39 


\section{LISTA DE ABREVIATURAS}

SFI= Índice Funcional do Ciático

$\mathrm{L}=$ grupo lesado

$\mathrm{L}+\mathrm{US}=$ grupo lesado tratado com ultra-som

$\mathrm{N}=$ Normal

$\mathrm{PL}=$ pré-lesão

$\mathrm{TA}=$ músculo Tibial Anterior

$\mathrm{SOL}=$ musculo Sóleo 


\section{SUMÁRIO}

\section{Resumo}

\section{Abstract}

\section{Lista de Figuras}

\section{Lista de Tabelas}

\section{Lista de Abreviaturas}

1. INTRODUÇÃ

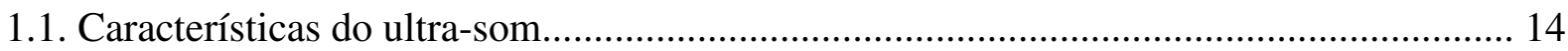

1.2. Ação do ultra-som em diferentes tecidos......................................................................... 16

1.3. Ultra-som pulsado de baixa intensidade interagindo com lesão nervosa

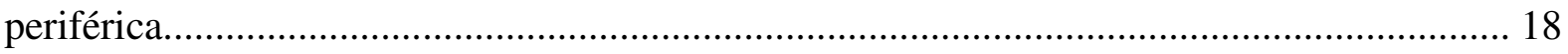

1.4. Lesão Nervosa Periférica e Alterações Neuromusculares.............................................. 22

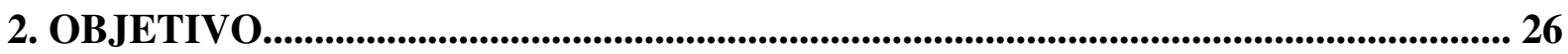

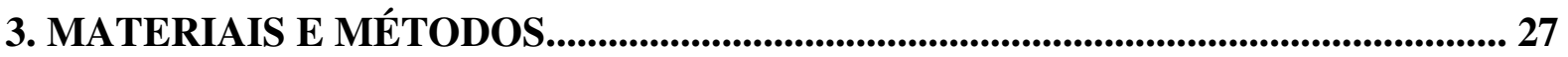

3.1. Animais e Grupos Experimentais............................................................................... 27

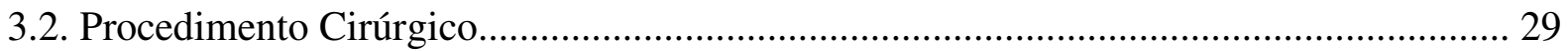

3.3. Protocolo de Tratamento com aplicação do ultra-som pulsado de baixa intensidade

3.4. Avaliação Funcional do Ciático (Análise da Marcha em Pista)........................................ 33

3.5. Análise Morfológica do Nervo Ciático, Músculos Tibial Anterior e Sóleo.........................36 


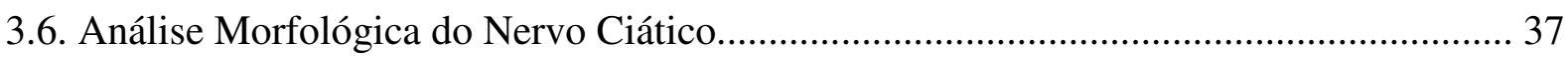

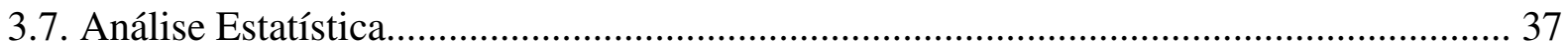

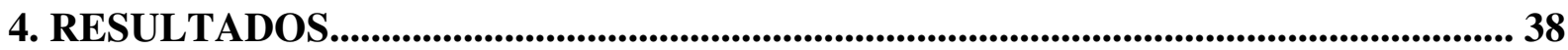

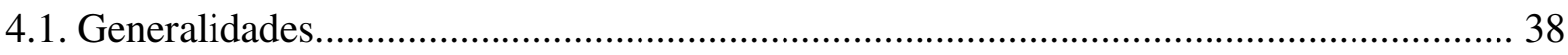

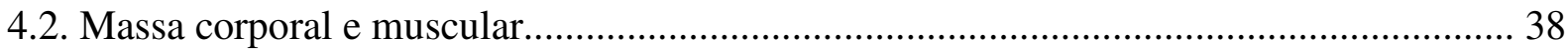

4.3. Análise morfológica e morfométrica da fibra muscular................................................ 39

4.4. Análise Morfológica do Nervo Ciático.............................................................................. 41

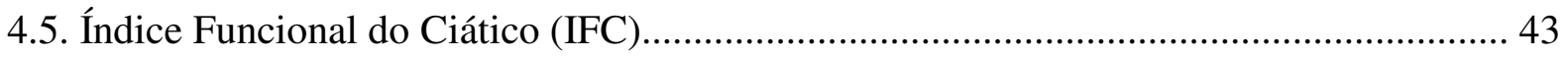

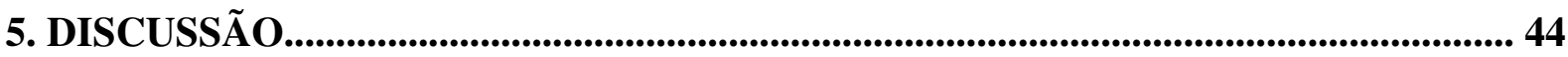

6. CONCLUSÃO

REFERÊNCIAS BIBLIOGRÁFICAS.............................................................................54

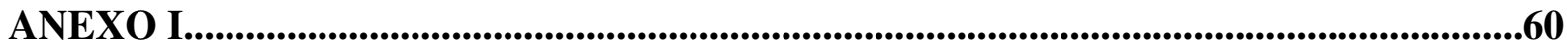

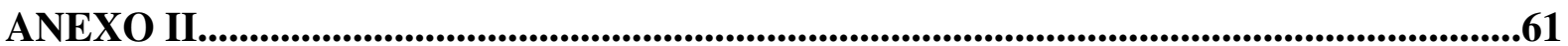




\section{INTRODUÇÃO}

O ultra-som é uma das formas de tratamento terapêutico, não-invasivo, que auxilia na regeneração nervosa periférica (CRISCI; FERREIRA, 2002). Além deste método terapêutico existem outros, também não-invasivos, como laser e eletroestimulação, que possuem agentes físicos importantes para reabilitação, influenciando positivamente nesse processo de melhora da função (MENDONÇA et al., 2003).

Dentre todas estas técnicas não-invasivas de regeneração nervosa periférica, pouco se sabe sobre a influência do ultra-som na regeneração desse tecido. Este fato direciona a investigar os efeitos do ultra-som pulsado de baixa intensidade e sua ação final sobre a regeneração nervosa periférica (CRISCI; FERREIRA, 2002).

Alguns pesquisadores estudaram o efeito do ultra-som sobre a regeneração nervosa periférica e vem obtendo resultados positivos, quando diz respeito aos parâmetros de baixa intensidade. Hong et al. (1988), reproduziram uma lesão compressiva no nervo tibial de ratos, em seguida, tratou com ultra-som, usando intensidades diferentes $\left(0,5\right.$ e $\left.1 \mathrm{~W} / \mathrm{cm}^{2}\right)$, freqüência de $1 \mathrm{MHz}$, duração de 1 minuto, 3 vezes por semana. Observaram que a recuperação da velocidade de condução motora foi melhor nos nervos tratados com a menor intensidade $\left(0,5 \mathrm{~W} / \mathrm{cm}^{2}\right)$, concluindo, portanto, que o ultra-som de baixa intensidade acelera a regeneração de nervos periféricos submetidos à lesão compressiva. $\mathrm{O}$ estudo de Lowdon et al. (1988), investigou o papel do ultra-som pulsado de baixa intensidade, com freqüência de $1 \mathrm{MHz}$ e intensidades diferentes $\left(0,5\right.$ e $1 \mathrm{~W} / \mathrm{cm}^{2}, 1$ minuto de aplicação, durante 2-3 semanas), utilizando o esmagamento, observaram resultados positivos se comparado aos nervos não-tratados, sendo o tempo de regeneração nervosa mais acentuada em $0,5 \mathrm{~W} / \mathrm{cm}^{2}$ do que $1 \mathrm{~W} / \mathrm{cm}^{2}$. Concluíram que o ultra-som de baixa intensidade acelera o 
processo de regeneração, mas se houver altas intensidades, pode resultar em atraso desta reparação nervosa.

Não foram encontrados muitos estudos in vitro que investigaram como ocorre especificamente a interação do ultra-som nos tecidos nervosos, assim como nas adjacências: músculos e vasos sangüíneos. Porém existem vários estudos, abaixo citados, que mostram diversos resultados de tratamento com o ultra-som em vários tecidos. Tais estudos foram importantes para ajudar a compreensão da atividade ultra-sônica nos mesmos. O presente estudo investigou o ultra-som pulsado de baixa intensidade interagindo com lesão nervosa periférica in vivo.

\subsection{Características do ultra-som}

O ultra-som é uma das terapias mais utilizadas no cotidiano clínico de um fisioterapeuta. Refere-se a uma forma de energia mecânica, dotada de ondas de pressão acústica, transmitida transcutaneamente aos tecidos biológicos.

O trabalho pioneiro sobre o ultra-som ocorreu na França, em 1917, Langevin observou a morte de peixes durante o desenvolvimento de um sonar. Nos Estados Unidos, em 1926 e 1927, Woods e Loomis estudaram o efeito letal do ultra-som em células, tecidos, peixes e rãs. Em 1940, Wall et al., em 1950 Fry e Fry, ambos nos Estados Unidos e 1960 Oka et al. no Japão, desenvolveram o ultra-som centralizado para aplicação in vitro, no sistema nervoso central (BAILEY et al., 2003). Desde a década de 40, na qual o ultra-som foi descoberto para aplicações na área médica, até os dias atuais, seus efeitos e aplicações vêm sendo motivo de várias pesquisas e discussões.

Docker (1987) referiu-se as freqüências altas (3MHz) como sendo as mais específicas para tratamento de tecidos superficiais, sendo a onda absorvida rapidamente, ao passo que as 
frequiências menores $(1 \mathrm{MHz})$ devem ser específicas para tecidos profundos, por penetrarem mais. Para ter Haar (1999) o ultra-som é dividido em duas categorias de aplicações: as que usam $0,125-3 \mathrm{~W} / \mathrm{cm}^{2}$ são consideradas baixa intensidade e aquelas onde o uso é maior ou igual a $5 \mathrm{~W} / \mathrm{cm}^{2}$ são altas intensidades. Já Doan et al. (1999), considerou intensidades baixas como sendo de 1 a 50mW/cm². Segundo Bailey et al. (2003), o ultra-som comumente usado na fisioterapia para aquecer tecidos em aproximadamente $1^{\circ} \mathrm{C}$, aplica a intensidade da ordem de $1 \mathrm{~W} / \mathrm{cm}^{2}$ e o tempo de tratamento por até10 minutos.

O objetivo terapêutico da aplicação de baixa intensidade nos tratamentos com ultra-som é para estimular respostas fisiológicas à lesão ou acelerar alguns processos, tais como o transporte de fármacos através da pele (ter HAAR; 1999).

Os efeitos biofísicos do ultra-som são dois, os térmicos e os não-térmicos. Barnett et al. (1997), relataram que o ultra-som induzindo aquecimento tecidual depende da amplitude do calor absorvido durante a terapia. A característica de absorção tecidual determina como o calor é depositado, ao passo que a composição e a extensão da vascularidade determinam como o calor é perdido do sistema por condução e perfusão. Os efeitos não-térmicos, classificados como terapêuticos, refere-se a micromassagem, sendo este um efeito natural do campo de pressão do som, o qual altera o gradiente de concentração na vizinhança da membrana extracelular. Desse modo, a micromassagem altera organelas e membranas celulares de maneira reversível ou irreversível, dependendo de sua magnitude. O tipo de célula e a alteração iônica produzida são fatores determinantes que podem desenvolver modificações na motilidade, síntese ou secreção celular, podendo acelerar o processo de regeneração (DYSON, 1987; ter HAAR 1999). Finalmente Backer et al. (2001), infere ser incorreto dizer que somente um efeito biofísico do ultra-som está presente durante o tratamento fisioterapêutico, ou seja, os dois efeitos não se separam, são classificados como termal (que é exposição à onda contínua) ou não-termal (que é exposição à onda pulsada). 
Isso dependerá da onda escolhida durante a terapia ultra-sônica. No presente estudo, os autores assumiram, para obterem efeito não-térmico, tipo de onda pulsado e intensidade de $40 \mathrm{~mW} / \mathrm{cm}^{2}$.

\subsection{Ação do ultra-som em diferentes tecidos}

O agente físico ultra-som é utilizado para auxiliar nos tratamentos das mais diversas disfunções dos tecidos moles, incluindo não só aplicação em osso e aceleração da cicatrização de feridas (ter HAAR, 1999), mas também, tendinites, bursites, espasmos músculoesqueléticos, redução de edema e dor (MAXWELL, 1992; GEOFFREY et al., 2002). Segundo Maxwell (1992), o ultra-som possue efeito sobre radicais livres, microcirculação, mediadores do processo inflamatório, infiltração celular e reparação dos tecidos moles. Podendo atuar com seus efeitos positivos sobre os tecidos e assim conferir aos mesmos, boa cicatrização.

Hogan et al. (1982), utilizaram ultra-som pulsado na freqüência de $1 \mathrm{MHz}$ e intensidades diferentes $\left(1,25\right.$ a $\left.10,0 \mathrm{~W} / \mathrm{cm}^{2}\right)$, por 5 minutos, em dias alternados, por 1 ou 3 semanas em músculos isquêmicos de ratos. Obtiveram resultados significativos através das análises histológicas com melhora do fluxo sanguíneo das arteríolas, nas fases aguda e crônica do músculo. A intensidade que aumentou o fluxo sanguíneo foi de $2,5 \mathrm{~W} / \mathrm{cm}^{2}$.

Dyson (1987), concluiu que o ultra-som na fase aguda pode estimular a liberação de agentes quimiotáxicos e a granulação celular durante a fase de proliferação celular, que acontece no $3^{\circ}$ dia pós-lesão. Com a exposição às ondas ultra-sônicas, os fibroblastos foram estimulados a sintetizar maior quantidade de colágeno, conferindo resistência à tração dos tecidos moles cicatrizados, disponibilizando, para tal, um tecido cicatricial mais forte e elástico. 
Cunha et al. (2001), demonstraram por meio do ultra-som de baixa intensidade (freqüência: $1 \mathrm{MHz}$, intensidade: $0,5 \mathrm{~W} / \mathrm{cm}^{2}$, por 5 minutos de aplicação, durante 14 dias consecutivos em ambas modalidades: pulsado e contínuo), em tendão de Aquiles tenotomizados de ratos que o modo pulsado estimulou a formação de regeneração tecidual com melhor agregação e alinhamento das bandas de colágeno no eixo tendíneo. Já o modo contínuo induziu uma diminuição no processo de cicatrização do tendão de Aquiles.

Igualmente, em tendões de ratos, Koeke et al. (2005), compararam a eficácia da aplicação tópica de hidrocortisona e a fonoforese com ultra-som pulsado terapêutico após tenotomia. O ultra-som possuía freqüência de $1 \mathrm{MHz}$ e intensidade de $0,5 \mathrm{~W} / \mathrm{cm}^{2}$ por 5 minutos de aplicação. Os resultados mostraram, após análise de microscopia de luz polarizada, que o tratamento com fonoforese foi o método mais eficiente e que as moléculas de colágeno respondem à estimulação ultra-sônica.

Em lesões musculares, Rantanen et al. (1999), observaram a velocidade de regeneração das fibras musculares do músculo gastrocnêmio de ratos, com o uso do ultra-som pulsado. Utilizaram técnicas morfométricas e imunohistoquímica, encontrando uma significativa proliferação de células satélites durante os primeiros estágios de regeneração.

Bassoli (2001) estudou o efeito do ultra-som pulsado na regeneração músculoesquelética em ratos, utilizou ultra-som pulsado após 3, 6 e 10 dias. Observou que o ultra-som pulsado de baixa intensidade acelera a regeneração de fibras musculares mediante a intensa neoformação vascular, acelerando a reparação de necrose e formação de mioblastos, formando novas células musculares.

Apesar dos resultados positivos, encontrados nas literaturas, sobre ultra-som de baixa intensidade na tentativa de melhorar e manter o trofismo muscular, sob condições de lesão, há estudo contrário. Recentemente, um estudo observou os efeitos do ultra-som não-termal (3MHZ, contínuo, 5 minutos de aplicação diariamente) e exercício (caminhada na esteira 
rolante por 20 minutos no dia da terapia com ultra-som) na regeneração músculo-esquelética. Analisaram a concentração de proteína contrátil, área de secção transversa e número de mionúcleo por fibra do músculo gastrocnêmio de rato. Concluíram que não foram encontradas evidências específicas e nem protocolos confirmando que o ultra-som intensifica o processo de regeneração músculo-esquelética (MARKERT et al., 2005).

Existem inúmeros estudos contraditórios sobre os efeitos do ultra-som em processo inflamatório. No tratamento de edemas, um estudo utilizou o protocolo com ultra-som pulsado (freqüência de $1 \mathrm{MHz}$ e intensidade de $0,4 \mathrm{~W} / \mathrm{cm}^{2}$ ) e tratamento farmacológico. Mostraram que a aplicação do ultra-som isoladamente não foi capaz de reduzir o edema, ao contrário do grupo que foi associado ao tratamento de ultra-som com fármacos o qual evidenciou redução do edema nas patas dos ratos (DURIGAN et al., 2006).

Apesar da grande quantidade de trabalhos sendo realizados no campo ultra-sônico interagindo com o meio biológico, existem poucos resultados no que diz respeito a parâmetros de dosimetria no tratamento específico da lesão nervosa periférica.

\subsection{Ultra-som pulsado de baixa intensidade interagindo com lesão nervosa periférica}

Em 1980 foi estudado o efeito do ultra-som terapêutico no nervo tibial esmagado de ratos. O tratamento com ultra-som foi realizado imediatamente após o quinto dia da lesão, com freqüência de $1 \mathrm{MHz}$, intensidades de $0,5 \mathrm{~W} / \mathrm{cm}^{2}$ e de $1 \mathrm{~W} / \mathrm{cm}^{2}$, por 1 minuto, 3 vezes por semana. Foram analisadas a latência motora distal, velocidade de condução motora e amplitude do potencial de ação muscular composto evocado, antes e após a lesão, sendo também medidas a cada duas ou três semanas depois. Observaram que a recuperação dos parâmetros com exceção da latência foi significativamente mais rápida nos nervos tratados na intensidade de $0,5 \mathrm{~W} / \mathrm{cm}^{2}$ do que no grupo simulado. Com a intensidade de $1 \mathrm{~W} / \mathrm{cm}^{2}$ a 
recuperação do potencial de ação muscular foi mais lenta, sem mudanças significativas dos outros parâmetros. Concluíram que o ultra-som com intensidade baixa pode facilitar a recuperação das neuropatias de compressão, mas com doses altas pode ter efeitos adversos (HONG et al., 1988).

Após vinte anos foi investigado o efeito do ultra-som no tratamento de latência distal do nervo mediano em humanos. A dosimetria do ultra-som foi variada em freqüência (1 e $3 \mathrm{MHz}$ ), ciclo de trabalho (pulsado e contínuo), mesma intensidade $1 \mathrm{~W} / \mathrm{cm}^{2}$ com duração da aplicação de 8 minutos. Mediante ao grupo, a aferição de temperatura do tecido subcutâneo e as latências sensitivas e motoras do nervo, antes e durante o tratamento (2 em 2 minutos até chegar em 8 minutos), resultou em alterações de latência do nervo que estavam mais relacionadas a efeitos da temperatura (térmicos) do que aos efeitos não-térmicos (mecânicos) (MOORE et al., 2000).

Um estudo em animais observou a influência do ultra-som sobre a regeneração do nervo ciático esmagado de ratos. Os parâmetros de aplicação do ultra-som foram variados em freqüência, intensidade e tempo de tratamento, por um período de 30 dias, três vezes por semana. O melhor protocolo de tratamento, o que acelerou a recuperação do nervo, apresentou os seguintes parâmetros: intensidade $0,25 \mathrm{~W} / \mathrm{cm}^{2}$, freqüência $2,25 \mathrm{MHz}$ e tempo de aplicação de 1 minuto (MOURAD et al., 2001).

Outro estudo em ratos verificou a ação benéfica do ultra-som na regeneração nervosa periférica. $\mathrm{O}$ tratamento do ultra-som pulsado de baixa intensidade (freqüência de $1,5 \mathrm{MHz}$ e intensidade de $16 \mathrm{~mW} / \mathrm{cm}^{2}$ ) num período de 12 dias durante 20 minutos, no nervo ciático suturado em término-terminal; promoveu a regeneração nervosa periférica demonstrada por meio de análises morfológicas evidenciando formação de novos vasos sanguíneos, poucas deformidades na bainha de mielina, estimulação das células de Schwann com aumento da atividade metabólica local (CRISCI; 2002), como visto na tabela 1. 
Um estudo comparou o processo de regeneração nervosa periférica usando enxerto

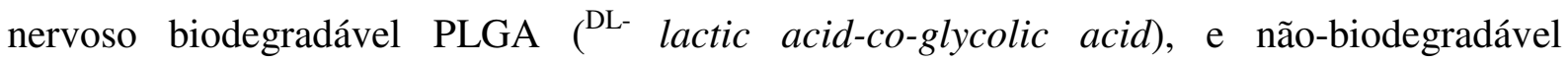
(silicone), associado ao ultra-som pulsado de baixa intensidade (freqüência de $1 \mathrm{MHz}$ e intensidade $0,2 \mathrm{~W} / \mathrm{cm}^{2}$ durante 5 minutos de aplicação por 12 dias), no nervo ciático lesado por esmagamento. Após 6 semanas de tratamento, através dos resultados histológicos positivos, obtiveram melhor regeneração nervosa com maior número e área de axônios mielinizados quando comparados ao grupo simulado; nos animais estimulados com ultra-som e enxerto biodegradável (CHANG; HSU, 2004), como visto na tabela 1.

O segundo estudo que também utilizou o método de tubulização teve como material de estudo tubos biodegradáveis e não-biodegradáveis com o objetivo de estudar os efeitos do ultra-som de baixa intensidade em modelos experimentais in vivo e in vitro de regeneração nervosa periférica (tabela 1). Para este estudo, os pesquisadores empregaram diferentes parâmetros de dosimetria de aplicação do ultra-som, porém a frequiência e o tempo de tratamento foram os mesmos ( $1 \mathrm{MHz}$ e 12 dias consecutivos, respectivamente) nos dois tipos de tubos (biodegradável e não-biodegradável). No estudo in vitro a aplicação do ultra-som contou com intensidade $0,05 \mathrm{~W} / \mathrm{cm}^{2}$, por 3 minutos, logo, no in vivo, a intensidade foi de $0,3 \mathrm{~W} / \mathrm{cm}^{2}$ e o tempo de 5 minutos. O material biodegradável associado ao ultra-som de baixa intensidade obteve um número significativo de axônios regenerados, comparados ao grupo simulado, já com os materiais não-biodegradáveis houve um retardo na regeneração axonal, podendo observar tecido fibroso cobrindo a condução na região nervosa. (CHANG et al., 2005).

Outro estudo mais recente sobre esmagamento do nervo ciático de rato (tabela 1), utilizou ultra-som de baixa intensidade (com freqüência de $1 \mathrm{MHz}$ e intensidade de $0,4 \mathrm{~W} / \mathrm{cm}^{2}$, num período de 10 dias por 10 minutos), constatou que melhorou a nutrição tecidual, aumentou a densidade de fibra nervosa, ativou célula de Schwann restaurando o tubo endoneural, 
estimulou a produção de axoplasma contribuindo para a regeneração nervosa (RASO et al., 2002, 2005, 2006).

Tabela 1 - Pesquisas sobre o efeito do ultra-som pulsado de baixa intensidade em diferentes freqüências, intensidades e tempo de tratamento em lesão nervosa periférica e seus respectivos autores.

\begin{tabular}{|c|c|c|c|}
\hline Referências & Tipo de Lesão & Parâmetros do Ultra-som & $\begin{array}{c}\text { Efeitos do Ultra-som } \\
\text { sobre a reparação } \\
\text { nervosa }\end{array}$ \\
\hline Crisci; 2002 & Neurotmese & $\begin{array}{l}\text { Freqüência: } 1 \mathrm{MHz} \text {; Tipo de onda: } \\
\text { Pulsado; Intensidade: } 16 \mathrm{~mW} / \mathrm{cm}^{2}\end{array}$ & $\begin{array}{l}\text { A regeneração } \\
\text { ocorreu de forma } \\
\text { mais normal } \\
\text { possível, mesmo } \\
\text { sendo um método } \\
\text { não-invasivo. }\end{array}$ \\
\hline $\begin{array}{l}\text { Chang; Hsu, } \\
2004\end{array}$ & Muscle-splitting & $\begin{array}{l}\text { Freqüuência: } 1 \mathrm{MHz} \text {; Tipo de onda: } \\
\text { Pulsado; Intensidade: } 0,2 \mathrm{~W} / \mathrm{cm}^{2}\end{array}$ & $\begin{array}{c}\text { O enxerto } \\
\text { biodegradável } \\
\text { obteve resultados } \\
\text { mais significativos } \\
\text { quando comparados } \\
\text { com o não- } \\
\text { biodegradável. }\end{array}$ \\
\hline $\begin{array}{l}\text { Raso et al., } \\
\quad 2005\end{array}$ & Axoniotmese & $\begin{array}{l}\text { Freqüência: } 1 \mathrm{MHz} \text {; Tipo de onda: } \\
\text { Pulsado; Intensidade: } 0,4 \mathrm{~W} / \mathrm{cm}^{2}\end{array}$ & $\begin{array}{l}\text { Melhorou a nutrição } \\
\text { tecidual, aumentou a } \\
\text { densidade de fibras } \\
\text { nervosas, ativou as } \\
\text { células de Schwann } \\
\text { e estimulou a } \\
\text { produção de } \\
\text { axoplasma. }\end{array}$ \\
\hline $\begin{array}{l}\text { Chang et al., } \\
2005\end{array}$ & Muscle-splitting & $\begin{array}{c}\text { Freqüência: } 1 \mathrm{MHz} \text {; Tipo de onda: } \\
\text { Pulsado; Intensidade: } 0,3 \mathrm{~W} / \mathrm{cm}^{2} \mathrm{e} \\
0,05 \mathrm{~W} / \mathrm{cm}^{2}\end{array}$ & $\begin{array}{c}\text { Encontraram } \\
\text { melhores resultados } \\
\text { com o PLGA, } \\
\text { biodegradável, } \\
\text { havendo } \\
\text { regeneração nervosa } \\
\text { mais significativa. }\end{array}$ \\
\hline
\end{tabular}




\subsection{Lesão Nervosa Periférica e Alterações Neuromusculares}

O profissional fisioterapeuta dá muita importância à reabilitação pós-lesão com a finalidade de garantir, a todos os pacientes, a suficiente recuperação da função neuromuscular. A utilização de agentes físicos como o ultra-som é importante para promoção da melhora da função e da regeneração nervosa periférica. Principalmente os nervos que percorrem os membros, são freqüentemente alvos de lesões traumáticas sendo danificados por esmagamentos, compressão, distensão, avulsão ou divisão e injúrias, resultando na interrupção da transmissão dos impulsos nervosos no local lesionado, perdendo sua função e incapacitando o indivíduo (AZZE; MATTAR, 2000; MILLESI, 2000).

Segundo dados de um estudo realizado nos EUA, 50 mil sujeitos sofrem lesões traumáticas nos nervos periféricos a cada ano (EVANS, 2001). A gravidade do dano nervoso pode resultar em perda ou diminuição da sensibilidade e motricidade da área inervada cuja severidade dependerá do acometimento de estruturas associado às dimensões do evento traumático (LUNDBORG, 2000; ENDO, 2002).

Numa compressão leve dos nervos periféricos, a continuidade axonal é geralmente preservada e a lesão pode ser classificada como neuropraxia tipo 1 na escala de Sunderland (1978) (ANEXO II). Isto indica um bloqueio local da condução nervosa, com boa possibilidade de recuperação funcional, em torno de poucas semanas ou meses.

Já numa compressão nervosa mais grave, na qual ocorre uma tração, ou até mesmo um rompimento das fibras nervosas, resulta-se em uma interrupção da continuidade axonal, tendo como conseqüência uma degeneração a partir da lesão, seguindo para todo o segmento distal, os tubos endoneurais permanecem íntegros, sendo classificadas como axoniotmese tipo 2 de Sunderland (1978) (ANEXO II). A regeneração axonal do segmento proximal é guiada por orientação intrínseca do tubo endoneural e ocorre a regeneração no sentido correto para a 
periferia. Segundo Machado (2004), uma lesão por esmagamento do nervo danifica ou mata os axônios distais ao local da lesão, os corpos das células neuronais normalmente sobrevivem e os revestimentos de tecido conectivo do nervo permanecem intactos, não havendo necessidade de nenhum reparo cirúrgico, pois as bainhas de tecido conectivo intactas guiam os axônios em crescimento até seus destinos. Portanto, após uma lesão desta natureza, pode-se esperar uma regeneração espontânea com uma excelente recuperação funcional (SEDDON, 1943; SUNDERLAND; 1978).

Quando o trauma é mais severo pode danificar os tubos endoneurais e os componentes conectivos (neurotmese do tipo 3 a 5 de Sunderland, 1978) (ANEXO II). Essa situação é mais grave em relação aos dois casos anteriores porque não existem estruturas que possam guiar a regeneração através da região da lesão, portanto, neste caso é necessária a intervenção cirúrgica.

Um tecido que é muito afetado após uma lesão nervosa periférica é o músculoesquelético. A inervação é um fator crítico para a integridade funcional e estrutural do músculo (ISHIDO et al., 2004; KOSTROMINOVA et al., 2005).

Investigações sobre a recuperação do músculo e o feedback natural dos músculos após lesão nervosa pode fornecer preciosas informações no processo de reabilitação após trauma nervoso (MARQUESTE et al., 2002). Gulati; Cole (1990) observaram que um músculo desnervado perde a habilidade para a reinervação e começa a atrofiar. A interação entre nervo e músculo durante desenvolvimento e regeneração é muito importante para uma formação bem sucedida do sistema neuromuscular funcional (KUREK et al., 1996).

A lesão nervosa periférica direciona em significativas mudanças no músculo, constituindo uma diminuição acentuada na massa muscular, na área de secção transversa das fibras musculares e uma queda na força contrátil (GORDON; MAO, 1994; CARLSON et al., 1996). Ainda, Bellington; Carlson (1996) e Down (2004), afirmaram que a lesão do nervo 
periférico causa uma profunda perda de massa e da capacidade de geração de força do músculo. A mudança neural que ocorre no músculo como resultado de lesão ou doença deriva em atrofia do músculo que pode, em parte, ser causada pela perda de fatores de crescimento produzidos por motoneurônios normalmente intactos (KUREK et al., 1996). Desnervação músculo-esquelética resulta em dano progressivo de suas propriedades funcionais, atrofia das fibras musculares e uma rápida diminuição de até $70-85 \%$ da massa tecidual durante os primeiros meses após a lesão (HNIK, 1962).

Quando o músculo se torna desnervado ocorrem inúmeras modificações na estrutura, metabolismo e expressão gênica do sistema músculo-esquelético. Uma mudança importante que ocorre quando os músculos tornam-se desnervados é o aumento de receptores de acetilcolina no sarcolema. Os receptores de acetilcolina são normalmente expressos na junção neuromuscular em músculos desnervados. Entretanto, a desnervação causa aumento e proliferação dos receptores de acetilcolina extrajuncionais. Alguns autores vêem isso como um tipo de "sinal" que causa brotamentos de novos axônios dos nervos e também como uma forma de preparação para a formação de uma nova junção neuromuscular (LIEBER, 2002).

Por causa de todos estes fatores envolvidos na lesão nervosa periférica, acima citados, a recuperação funcional após uma lesão é muito relativa, e nem sempre é satisfatória (LUNDBORG, 2000). Portanto, é necessário além de técnicas cirúrgicas, o uso de meios físicos que auxiliem no melhor prognóstico de reabilitação funcional. O ultra-som é uma das técnicas fisioterapêuticas que auxiliam na reabilitação neuromuscular após lesão. Porém, existem poucos trabalhos que estudam a eficácia do ultra-som na regeneração nervosa periférica (RASO et al., 2006). Com o objetivo de contribuir para aumentar os conhecimentos específicos na área de reabilitação por meio do ultra-som focalizando atenção especial na escolha dos parâmetros (dosimetria) corretos, os quais são aspectos relevantes nas perspectivas de aplicação em pacientes, o presente estudo investigará a influência do ultra- 
som pulsado de baixa intensidade na regeneração nervosa periférica, após lesão por esmagamento, realizada mediante a uma pinça com pressão de 9MPa (BEER et al., 2001), e recentemente padronizada por Artur Varejão da Universidade Trás-os-Montes e Alto Douro de Vila Real (VAREJÃO et al., 2003). 


\section{OBJETIVO}

Avaliar o efeito da terapia do ultra-som pulsado de baixa intensidade com freqüência de $1,5 \mathrm{MHz}$, intensidade de $40 \mathrm{~mW} / \mathrm{cm}^{2}$, largura de pulso de $200 \mu \mathrm{s}$, frequiência de pulso de $1 \mathrm{KHz}$ e potência de $140 \mathrm{~mW} / \mathrm{cm}^{2}$, em regeneração nervosa periférica, após lesão por esmagamento do nervo ciático de rato. 


\section{MATERIAIS E MÉTODOS}

\subsection{Animais e Grupos Experimentais}

Foram utilizados 26 ratos da raça Wistar, machos, adultos jovens com idade aproximada de 3 meses e massa corporal média de 289,61g. Uma boa prática laboratorial animal foi adotada de acordo com os padrões internacionais e nacionais para experimentação animal e aprovado pelo comitê de Ética em Experimentação Animal da UFSCar, sob o protocolo número 004/2006 (ANEXO I). Os animais foram mantidos em sala climatizada, em gaiolas de polipropileno contendo 3 animais em cada uma e ciclo de luz controlado (12 horas claro e 12 escuro). Os animais foram alimentados com ração padrão do biotério, sem restrições alimentares e água ad libitum. A figura 1 expõe um fluxograma dos procedimentos realizados.

Os grupos experimentais foram divididos através de uma rápida análise estatística de acordo com a massa corporal de cada animal, para que os grupos se tornassem os mais homogêneos possíveis. Assim, foram separados em 3 grupos experimentais até o dia do sacrifício, ou seja, no $28^{\circ}$ dia pós-operatório:

Grupo 1 (lesado + ultra-som): aplicação do ultra-som pulsado de baixa intensidade no membro inferior direito, lesada por esmagamento, $n=09$.

Grupo 2 (lesado): 0 membro inferior direito recebeu tratamento simulado, $\mathrm{n}=09$.

Grupo 3 (normal): sem qualquer tipo de lesão e intervenção, $n=08$.

O protocolo experimental do estudo foi desenvolvido no Laboratório de Eletrotermofototerapia da Universidade Federal de São Carlos (UFSCar). 


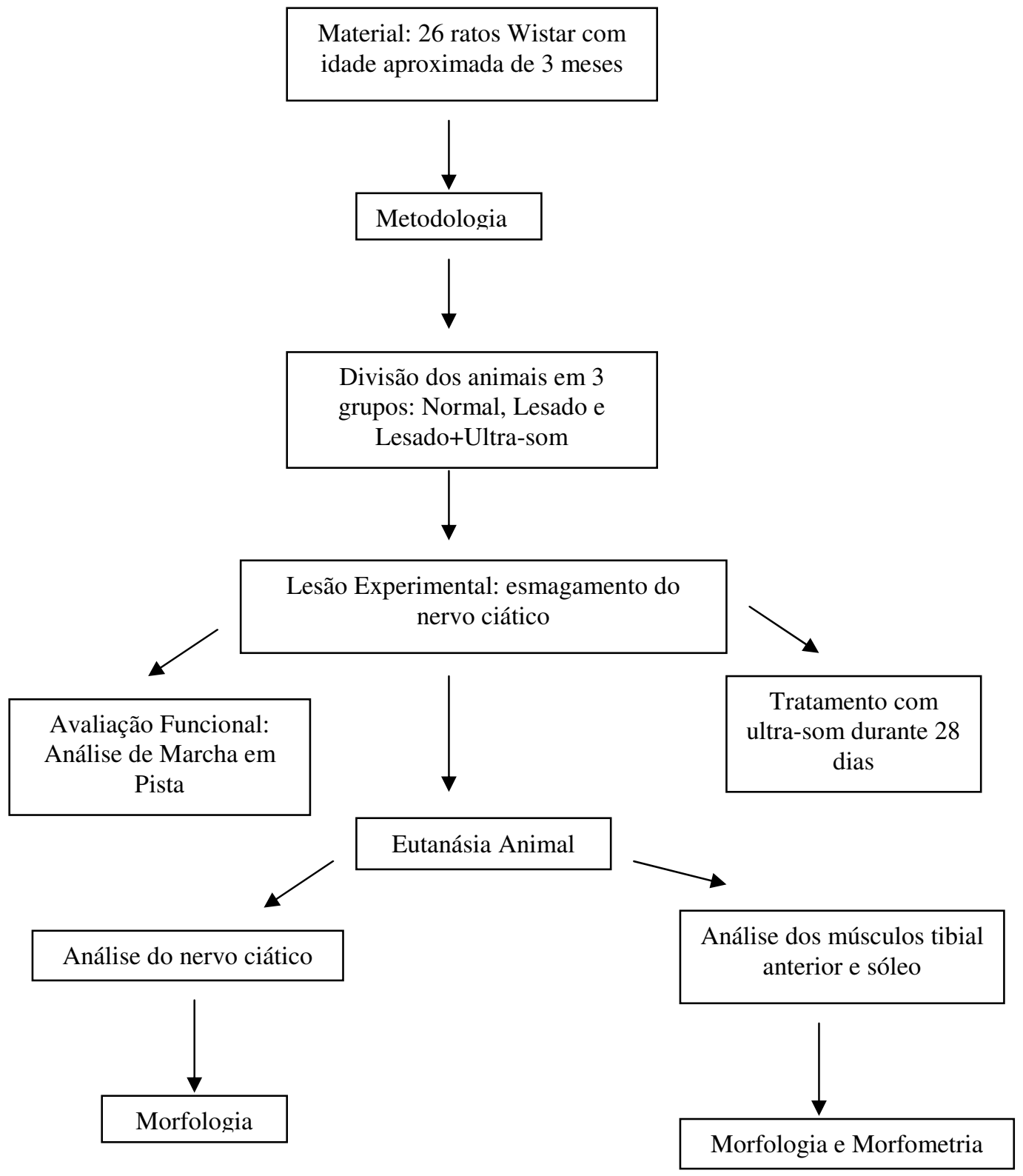

Figura 1 - Roteiro simplificado do procedimento experimental realizado 


\subsection{Procedimento Cirúrgico}

A realização da cirurgia seguiu os princípios éticos da experimentação animal (COBEA, 1991), sob condições padrões de anestesia geral e assepsia.

Os animais dos grupos 1 e 2 foram pesados para o cálculo da dose de anestesia e identificados. Em seguida foram anestesiados com injeção intraperitonial contendo Ketamina $(95 \mathrm{mg} / \mathrm{kg})$ e Xilasina $(12 \mathrm{mg} / \mathrm{kg})$. Após a anestesia, os animais foram posicionados em decúbito ventral, imediatamente foi realizada tricotomia na face posterior do membro inferior direito e assepsia com solução de iodo povidine (10\%). Logo após realizou uma incisão longitudinal na face posterior da coxa, com aproximadamente dois centímetros de comprimento, para visualização do nervo ciático. Subseqüentemente foi realizada uma lesão utilizando uma pinça que exerceu uma tensão de 9MPa por um período de 30s (figura 2A), ao longo de $3 \mathrm{~mm}$ do comprimento do nervo ciático, $10 \mathrm{~mm}$ acima da sua bifurcação (figura 2B) (VAREJÃO et al., 2003).

Após a lesão do tipo esmagamento, os músculos e a pele foram suturados com pontos simples de fio monofilamento de nylon $6 / 0$ e $4 / 0$, respectivamente. A ferida foi esterilizada com rifomicina, sem nenhum curativo. Nos três primeiros dias pós-operatórios, os animais receberam associados à água, $13,5 \mathrm{mg} / 100 \mathrm{ml}$ de gotas de paracetamol, para amenizar a dor.

Durante todo o procedimento cirúrgico, o campo da cirurgia foi mantido úmido com solução fisiológica estéril a 0,9\%, a uma temperatura corporal de aproximadamente $37^{\circ} \mathrm{C}$. 

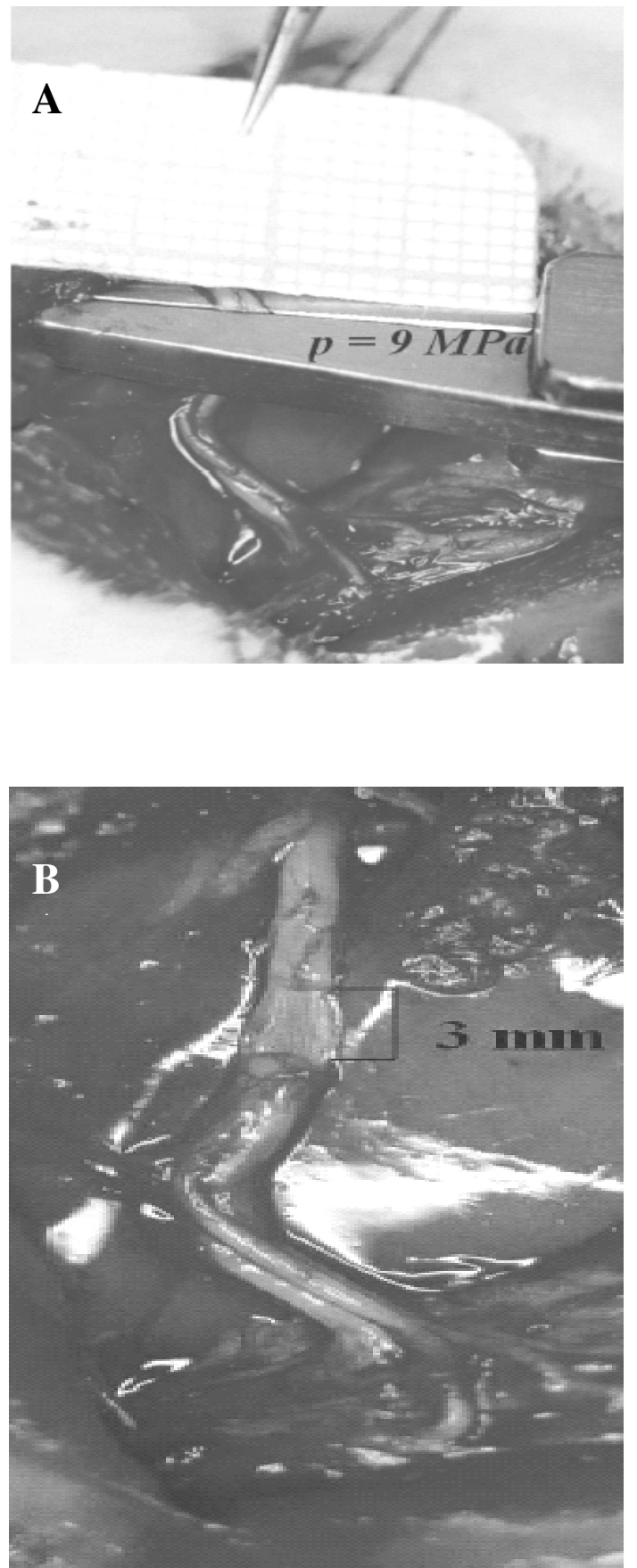

Figura 2A: Pinça utilizada para o procedimento de esmagamento do nervo ciático, exercendo pressão de $9 \mathrm{MPa}$

B: nervo ciático esmagado, 3mm ao longo do nervo ciático. Imagens cedidas por Varejão, 2003. 


\subsection{Protocolo de Tratamento com aplicação do ultra-som pulsado de baixa intensidade}

A realização do protocolo de tratamento do ultra-som pulsado de baixa intensidade foi efetivada com um aparelho de patente requerida (PI 0402649-7 de 01/07/2004 - Processo de tratamento da Osteoporose não invasivo e sem regime medicamentoso). Este aparelho de ultra-som (figura 3) usa transdutor de titanato zirconato de chumbo (PZT) e área do cabeçote de $3,88 \mathrm{~cm}^{2}$, utilizando os parâmetros:

- Freqüência fundamental: $1,5 \mathrm{MHz}$;

- Intensidade: $40 \mathrm{~mW} / \mathrm{cm}^{2}$;

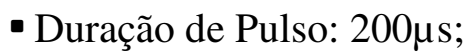

- Freqüência de Pulso: 1KHz;

- Potência: 140mW;

- Área de Radiação Efetiva (ERA): $5,83 \mathrm{~cm}^{2}$.

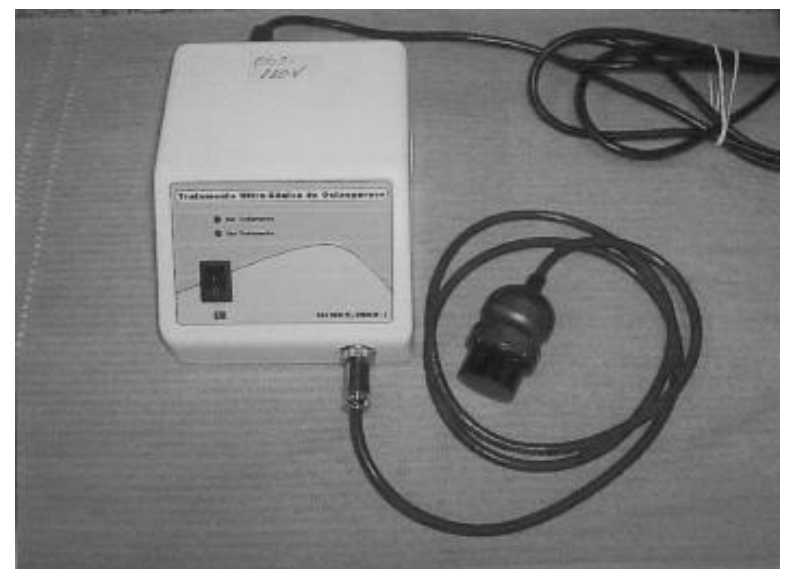

Figura 3: Aparelho de ultra-som utilizado na pesquisa.

Para intensificar o acoplamento do cabeçote à pele do animal, a região lesada (da cicatriz) foi tricotomizada (figura 4) todos os dias de tratamento. 


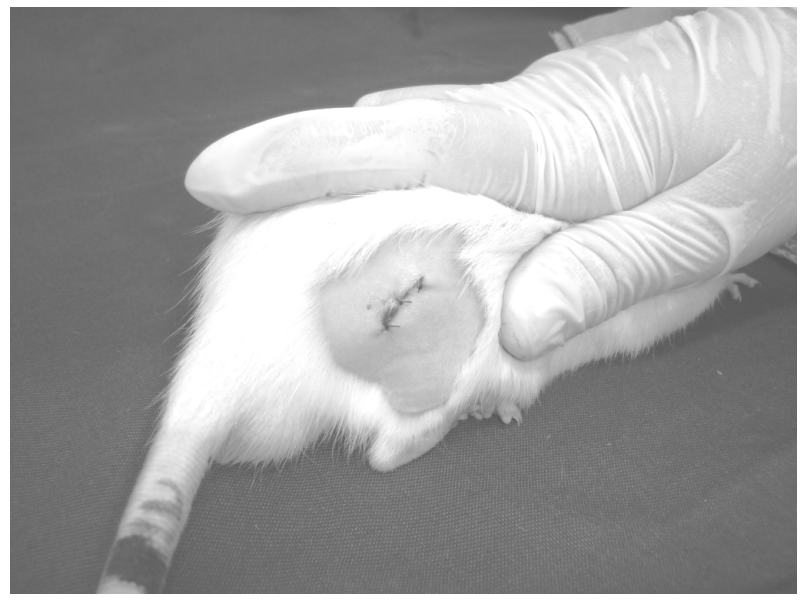

Figura 4: Região da coxa tricotomizada para a aplicação ultra-sônica.

Durante a terapia ultra-sônica, o animal foi imobilizado pelo dorso, com uma das mãos do pesquisador, fixando-o com um tecido, afim de isolamento visual, permanecendo imóvel a coxa direita, a qual recebeu as ondas ultra-sônicas (figura 5). Foi utilizado um gel de acoplamento para fins de transmissão da onda ultra-sônica. A aplicação do ultra-som de baixa intensidade foi de 8 minutos em dias intercalados, totalizando 14 aplicações do ultra-som, sempre no período vespertino, durante 28 dias. Estas aplicações foram realizadas nos grupos lesado e lesado+ultra-som, no grupo lesado, o cabeçote do ultra-som, desligado, acoplou a pata direita, simulando um tratamento terapêutico. Enquanto que no grupo lesado+ultra-som, este procedimento realmente ocorreu, sendo assim, o ultra-som ligado, emitiu ondas para o local lesado. O aparelho foi aferido toda a semana, por um dosímetro, com o intuito de assegurar um bom tratamento terapêutico ultra-sônico. 


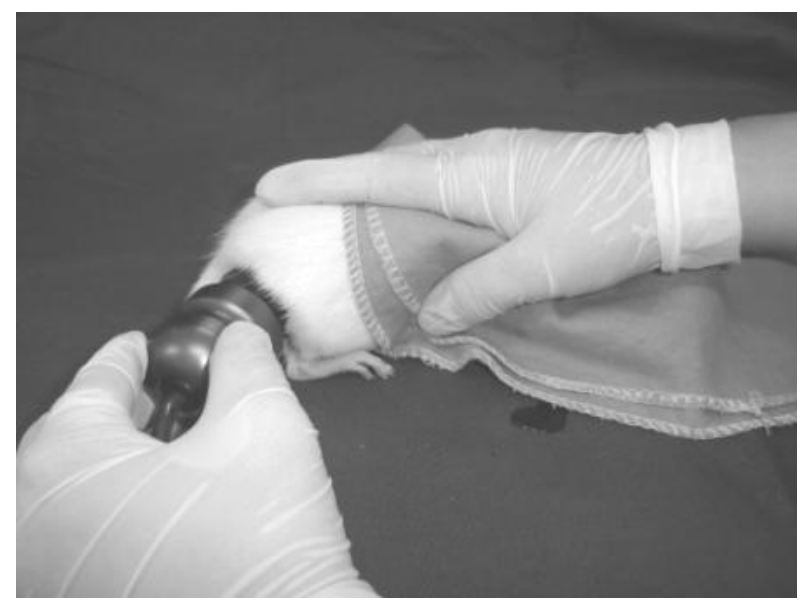

Figura 5: Aplicação da terapia ultra-sônica, a imobilização animal por um tecido e uma das mãos fixando o dorso, conservando imóvel a pata experimental.

\subsection{Avaliação Funcional do Ciático (Análise da Marcha em Pista)}

O modelo de avaliação funcional do nervo ciático foi obtida por meio do Índice Funcional do Ciático sendo calculado de acordo com a equação proposta por Bain et al. (1989).Os animais foram treinados a caminhar em um corredor com dimensões de $42 \mathrm{~cm}$ de comprimento, $8,2 \mathrm{~cm}$ de largura e com uma caixa escura ao fundo do corredor. Um papel branco foi colocado cobrindo o assoalho do corredor para que o animal pudesse caminhar sobre ele. As patas posteriores foram pressionadas sobre uma plataforma lisa encharcada de tinta de impressão digital (figura 6 A). Assim as impressões destas patas traseiras puderam ser marcadas no papel quando o rato realizava a travessia ao longo do corredor (figura 6 B).

Três medidas foram obtidas a partir das impressões destas patas (1) PL= impressão do comprimento da pata, ou seja, a distância do $3^{\circ}$ dedo ao calcâneo; (2) TS = afastamento dos dedos, ou seja: a distância do $1^{\circ}$ ao $5^{\circ}$ dedo; (3) ITS = afastamento intermediário dos dedos, ou seja, distância do $2^{\circ}$ ao $4^{\circ}$ dedo. Depois de realizadas todas as medidas tanto na pata experimental (E) quanto na normal $(\mathrm{N})$ o índice funcional do ciático foi calculado de acordo com a equação proposta por Bain et al. (1989): 
$S F I=-38.3\left(\frac{E P L-N P L}{N P L}\right)+109.5\left(\frac{E T S-N T S}{N T S}\right)+13.3\left(\frac{E I T S-N I T S}{N I T S}\right)-8.8$

onde: $\mathrm{EPL}=$ distância do $3^{\circ}$ dedo ao calcâneo da pata experimental

NPL= distância do $3^{\circ}$ dedo ao calcâneo da pata normal

$\mathrm{ETS}=$ distância do $1^{\circ}$ ao $5^{\circ}$ dedo da pata experimental

NTS $=$ distância do $1^{\circ}$ ao $5^{\circ}$ dedo da pata normal

EITS $=$ distância do $2^{\circ}$ ao $4^{\circ}$ dedo da pata experimental

NITS $=$ distância do $2^{\circ}$ ao $4^{\circ}$ dedo da pata normal

O mesmo animal caminhava no mínimo, três vezes pela passarela, para obter a melhor impressão das patas. As tiras de papel sulfite foram devidamente identificadas e deixadas a secar por 12 horas. Este procedimento, de coleta das impressões das patas, ocorreu antes da cirurgia, no $1^{\circ}, 5^{\circ}, 7^{\circ}, 12^{\circ}, 15^{\circ}, 19^{\circ}, 22^{\circ}$ e $27^{\circ}$ dias pós-operatórios. 

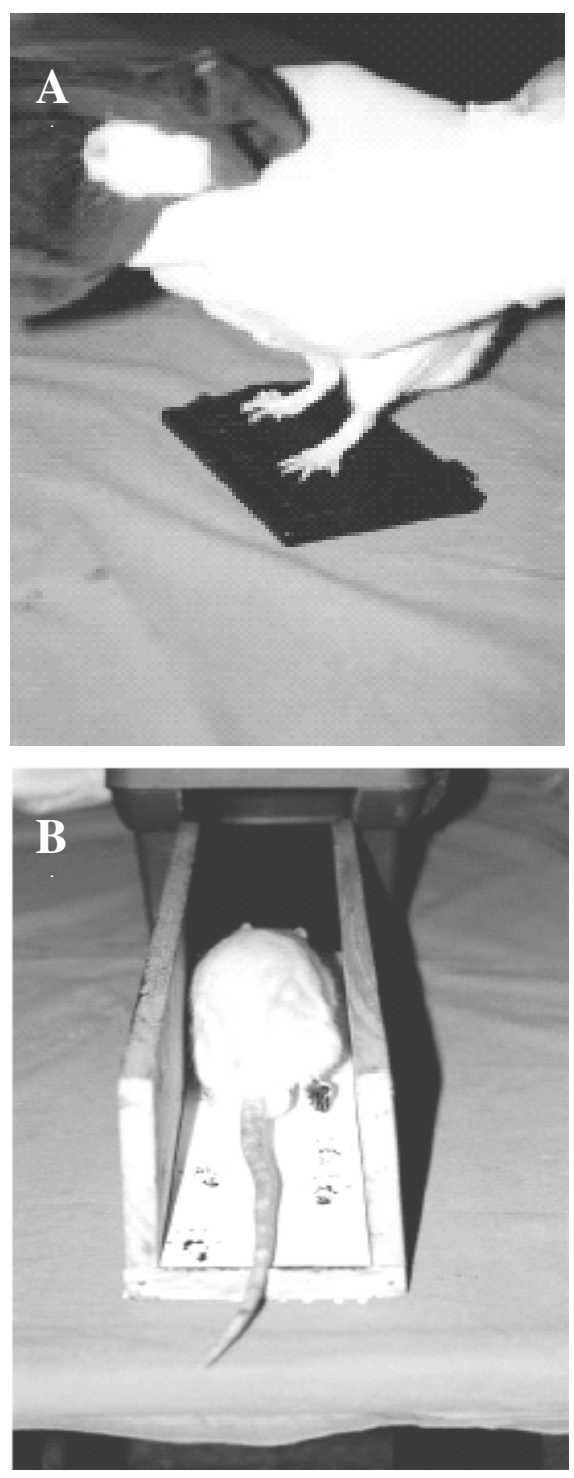

Figura 6A: Procedimento realizado para a impregnação das patas dos ratos, as quais eram depositadas na tinta de impressão digital. B: Vista das pegadas dos animais caminhando pela passarela, após impregnação das patas com tinta de impressão digital. Imagens cedidas por Varejão, 2003.

O SFI é sempre negativo, o normal é igual a 0 (zero), ausência de disfunção do nervo, ao passo que quando apresentar um índice igual a - 100 significa completa disfunção, portanto, quanto mais próximo de zero o índice chegar, melhor desempenho funcional do ciático. 


\subsection{Análise Morfológica e Morfométrica dos Músculos Tibial Anterior (TA) e Sóleo (SOL)}

Ao final de 28 dias, os animais foram anestesiados com Ketamina (95 mg/kg) e Xilasina (12 mg/kg), para a delicada dissecação dos músculos TA e SOL, ambos direito, posteriormente, os animais foram eutanasiados, promovendo, desta forma, o mínimo de estresse.

O processo de análise morfológica e morfométrica dos músculos TA direito e SOL o direito foi realizado no laboratório de Plasticidade Muscular, departamento de Fisioterapia da Universidade Federal de São Carlos.

Os músculos TA e SOL foram retirados, rapidamente pesados (para primeiros indícios de variações tróficas) e congelados em isopentano previamente resfriado em nitrogênio líquido, guardados em um freezer com $-86^{\circ} \mathrm{C}$, individualmente, em um refratário, devidamente identificados. Posteriormente, foi realizado nos músculos TA e SOL, cortes histológicos seriados $(10 \mu \mathrm{m})$, no ventre do músculo, em micrótomo criostato (MICROM 505ME, Carl Zeiss), mantido a temperatura de $-25^{\circ} \mathrm{C}$. Estes cortes foram corados com azul de toluidina (TB) para análise de morfologia geral e também para morfometria. Uma vez os cortes corados com azul de toluidina, foi realizada análise morfológica geral da estrutura muscular, podendo com isso, comparar entre os diferentes grupos. A morfometria das fibras musculares foi avaliada em microscopia de luz, usando para tal o software Axion Vision (Carl Zeiss). Com isso, cento e cinqüenta fibras musculares foram escolhidas aleatoriamente, dentro de um campo delimitado, de cada músculo TA e SOL e mensuradas a partir da imagem obtida da região central do ventre muscular. 


\subsection{Análise Morfológica do Nervo Ciático}

O mesmo procedimento ocorreu para a retirada do nervo ciático, ou seja, os animais foram anestesiados com Ketamina (95 mg/kg) e Xilasina $(12 \mathrm{mg} / \mathrm{kg})$, para a sua delicada dissecação e posteriormente, foram eutanasiados, promovendo, desta forma, o mínimo de estresse.

O processo de análise morfológica do nervo ciático direito foi realizado nos laboratórios de Plasticidade Muscular (Departamento de Fisioterapia), Anatomia, Hidrobiologia e Efetrotermofototerapia da Universidade Federal de São Carlos.

O nervo ciático foi retirado e embebido na solução formol, permanecendo por 3 horas. Após esse tempo, o nervo foi lavado em 3 banhos de PBS a cada 10 minutos, finalmente, o mesmo era colocado no álcool 70\%. Para posterior análises morfológicas, foram retirados do álcool 70\%, desidratados e inclusos em parafina. Desta forma, emblocados perpendiculares ao seu eixo principal, em uma fôrma de papel, devidamente identificados. Em seguida, foram feitos cortes histológicos seriados $(7 \mu \mathrm{m})$ em micrótomo (American Optical), com temperatura ambiente.

Para análise de morfologia geral, os cortes foram corados com tricômio de Masson e analisados em microscopia de luz Axion Vision (Carl Zeiss). Mediante a tal processo, pode-se realizar comparações entre os diferentes grupos.

\subsection{Análise Estatística}

Para análise estatística deste trabalho, a priori foi submetido a testes de Homogeneidade (Levene) e Normalidade. Feito isso, foi aplicado o teste de variância ANOVA One-Way, seguida pelo teste de Tukey e t não-pareado para detectar as diferenças entre os grupos. O nível de significância mínimo estabelecido foi de 5\%. O software utilizado foi Excel. 


\section{RESULTADOS}

\subsection{Generalidades}

Os animais nos primeiros dias pós-operatórios apoiavam-se parcialmente sobre a pata lesada, apresentavam adução dos dedos e pata caída. Decorridos alguns dias do tratamento com ultra-som, os animais foram, gradualmente recuperando o apoio sobre o membro direito, ou seja, o lesado.

\subsection{Massa corporal e muscular}

A análise da massa corporal mostrou que todos os animais ganharam peso ao longo de 28 dias de experimento (Tabela 2) quando comparado à massa corporal inicial $(\mathrm{p}<0,05)$, sendo que não houve diferença entre a massa corporal nos diferentes grupos até 28ㅇ dia $(\mathrm{p}>0,05)$.

A lesão do nervo ciático provocou uma diminuição da massa muscular tanto no grupo L (TA: redução de 25,74\%, p= 0,0003; SOL: redução de 17,63\%, p= 0,0009) quanto em L+US (TA: redução de 29\%, p= 0,0002; SOL: redução de 27,8\%, p=0,0004) quando comparados ao grupo N. Não houve diferença entre os grupos L e L+US (TA, p= 0,76; SOL, $\mathrm{p}=0,99$, respectivamente; Tabela 2) 
Tabela 2: Massa corporal e dos músculos tibial anterior (TA) e sóleo (SOL).

\begin{tabular}{ccccc}
\hline & $\begin{array}{c}\text { Massa } \\
\text { Corporal } \\
\text { Inicial (g) }\end{array}$ & $\begin{array}{c}\text { Massa } \\
\text { Corporal } \\
\text { Final (g) }\end{array}$ & Massa TA (g) & $\begin{array}{c}\text { Massa SOL } \\
(\mathbf{g})\end{array}$ \\
\hline $\mathbf{N}$ & $282,1 \pm 30$ & $339 \pm 16^{*}$ & $0,65 \pm 0,05$ & $0,24 \pm 0,01$ \\
$\mathbf{L}$ & $285,6 \pm 28,8$ & $334 \pm 19,6^{*}$ & $0,49 \pm 0,05^{\dagger}$ & $0,19 \pm 0,05^{\dagger}$ \\
$\mathbf{L}+\mathbf{U S}$ & $277,7 \pm 33$ & $337,5 \pm 25,7^{*}$ & $0,46 \pm 0,04^{\dagger}$ & $0,17 \pm 0,02^{\dagger}$ \\
\hline
\end{tabular}

Em que: N, grupo normal; L, grupo lesado 28 dias; L+US, grupo lesado tratado com ultra-som em dias alternados durante 28 dias. ${ }^{*} \mathrm{p}<0,05$ : comparados aos valores de massa corporal inicial. ${ }^{\dagger} \mathrm{p}<0,05$ : comparado ao grupo N. Note: há uma perda significativa da massa muscular nos grupos L e L+US.

\subsection{Análise morfológica e morfométrica da fibra muscular}

A análise morfológica dos músculos TA e SOL (Fig. 7) mostrou a estrutura normal da fibra muscular nos grupos N (Fig. 7A e B), com núcleos periféricos às fibras musculares e a arquitetura poligonal da fibra muscular bem delimitada. Já nos grupos L (Fig. 7C e D) e L+US (Fig. 7E e F) observa-se uma atrofia das fibras musculares, com aproximação dos mionúcleos e proliferação do tecido conjuntivo. 

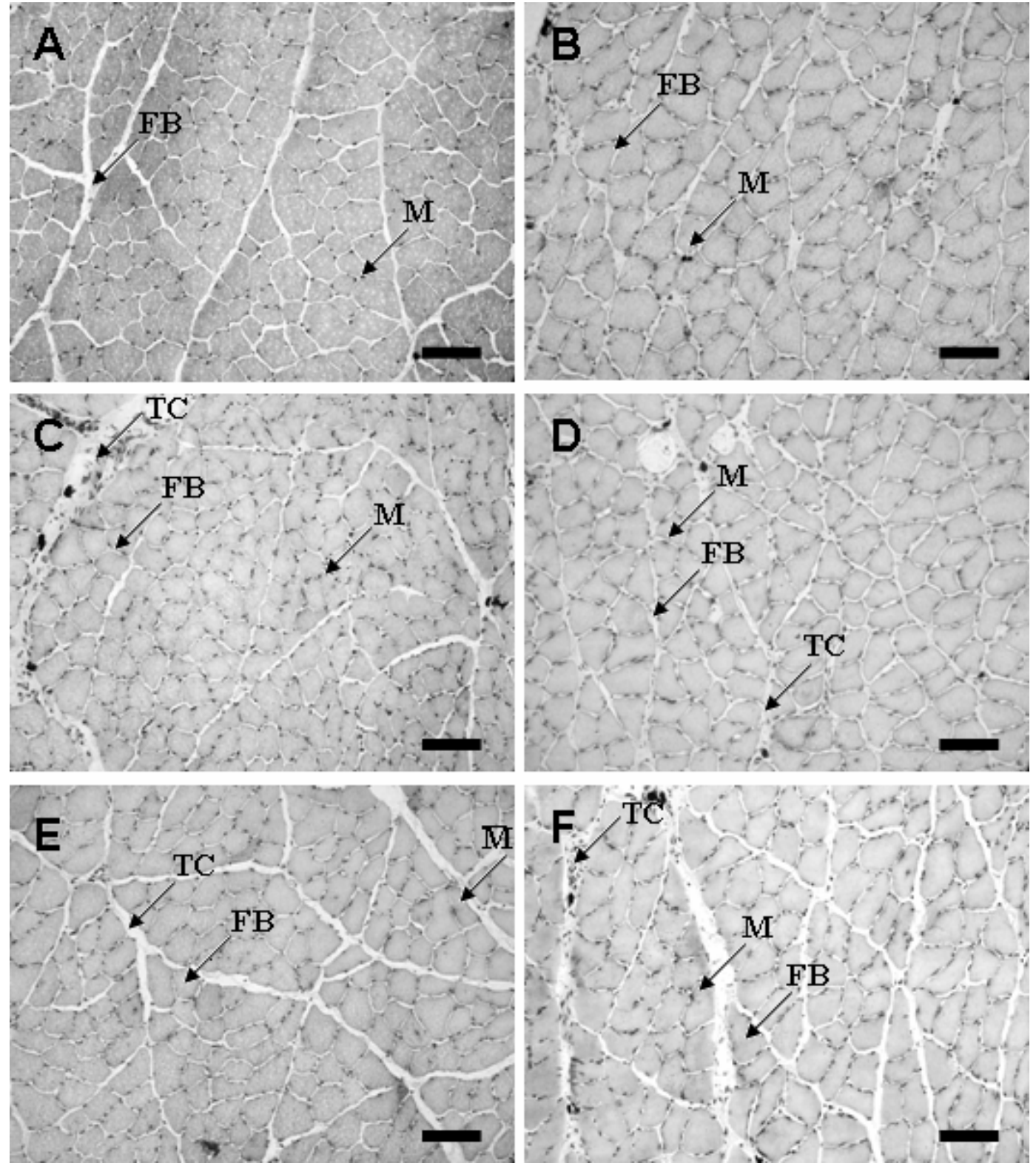

Figura 7: Fotomicrografia de cortes histológicos de secção transversal dos músculos tibial anterior (TA) e sóleo (SOL) corados com azul de toluidina. A e B) TA e SOL normais, respectivamente; $\mathrm{C}$ e D) TA e SOL do grupo L, respectivamente; E e F) TA e SOL do grupo L+US. Observe uma diminuição da área de secção transversa das fibras musculares (FB), proliferação do tecido conjuntivo (TC) e aproximação dos mionúcleos (M) nos grupos lesados (L e L+US). Barra: $100 \mu \mathrm{m}$.

Houve uma redução significativa da área de secção transversa (AST) das fibras musculares no grupo L do músculo TA (redução de 24,85\%, p=0,0430) e L+US não apresentou perda da AST ( $\mathrm{p}=0,617$ ), comparados ao músculo normal (Fig. 8A). Já no 
músculo SOL não houve diferença entre a AST e esses dois grupos - L $(p=0,183)$ e L+US $(\mathrm{p}=0,831)$ comparados ao músculo normal (Fig. 8B).

A

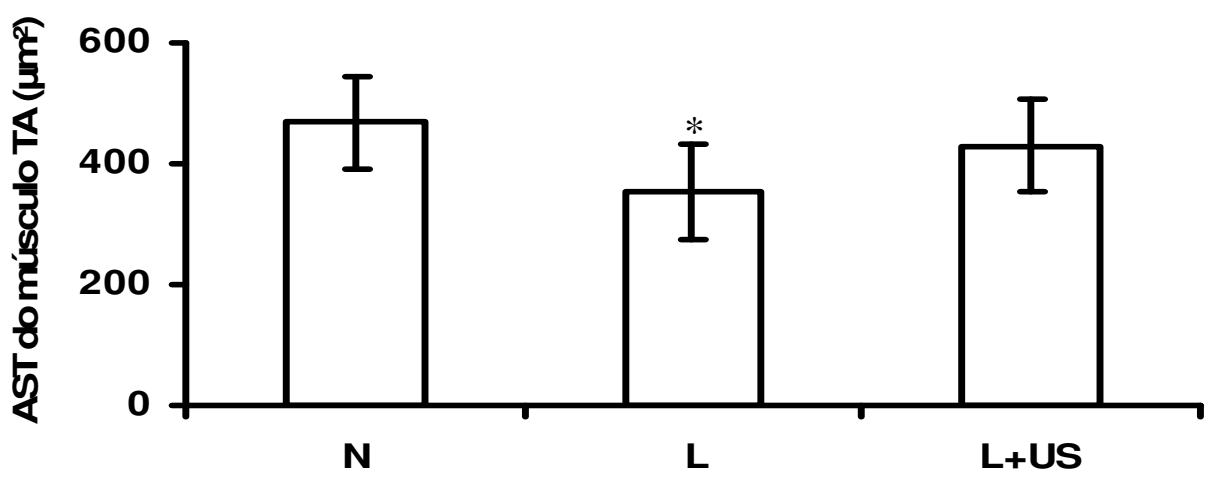

B

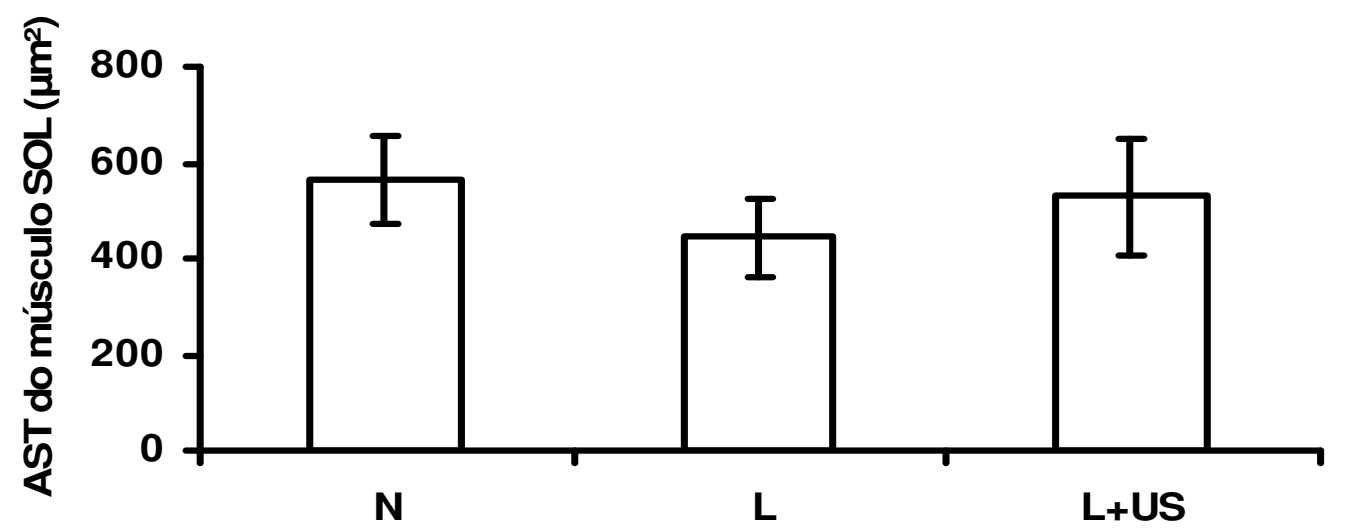

Figura 8: Área de secção transversa (AST) das fibras musculares dos músculos tibial anterior (A) e sóleo (B). Em que: N, grupo normal; L, grupo lesado 28 dias; L+US, grupo lesado tratado com ultra-som em dias alternados durante 28 dias. ${ }^{*} \mathrm{p}<0,05$ : comparados aos valores normais $(\mathrm{N})$.

\subsection{Análise Morfológica do Nervo Ciático}

A análise morfológica dos nervos ciáticos esmagados e normais através de microscopia de luz (Fig. 9A, B e C) mostrou que os nervos dos grupos lesado+ ultra-som e 
lesados não apresentaram diferenças morfológicas entre eles, tanto de estrutura dos axônios e organização celular, número de fibras, quanto de espessura de bainha de mielina e dos axônios. Todavia quando os nervos dos grupos experimentais são comparados morfologicamente com os do grupo normal vimos que estruturalmente são desorganizados com muito tecido amorfo e fibroso, com diâmetro do axônio e bainhas de mielinas menores em relação ao grupo normal (Fig. 9A, B e C).
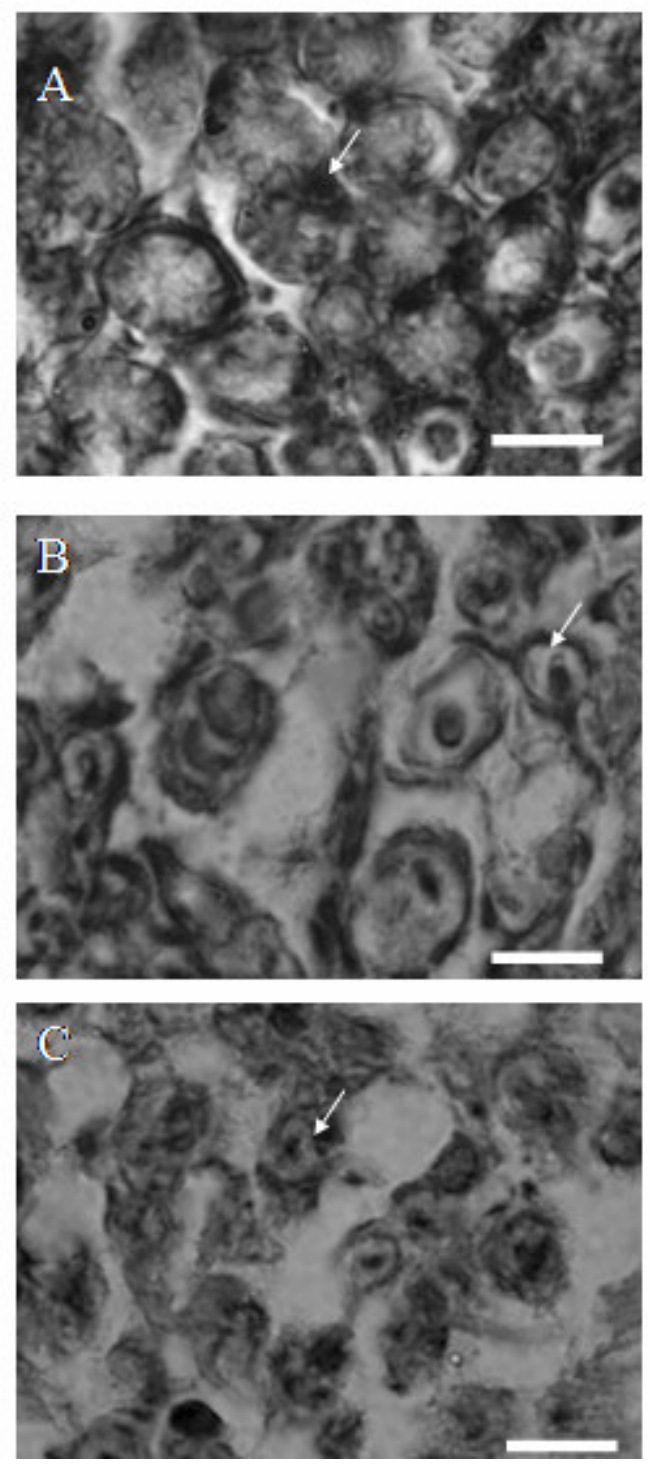

Figura 9: Fotomicrografia de corte transversal histológico do nervo ciático corado com tricômio de masson. Nervo Ciático do rato A (normal) é visível a maior quantidade de axônios no campo, além de maior diâmetro das fibras, a bainha de mielina envolve todos os axônios. No quadro B (lesado+tratado) e C (lesado) os diâmetros das fibras são menores e existem menos fibras por campo. Escala da barra: $40 \mu \mathrm{m}$. 


\section{5. Índice Funcional do Ciático (IFC)}

Os valores pré-lesão foram considerados como valores normais. Uma diminuição significativa do IFC ocorreu nos grupos L e L+US ( $p=0,0001$ e $p=0,0001$, respectivamente) comparados aos valores normais, no primeiro dia após a lesão nervosa (Fig.10). Essa redução se mantém nos grupos lesados durante a primeira semana. A partir do 12º dia, há uma recuperação da função da pata do animal, mas seus níveis ainda são inferiores aos valores normais ( $\mathrm{L}, \mathrm{p}=0,0001 ; \mathrm{L}+\mathrm{US}, \mathrm{p}=0,0001$; Fig. 10). Apenas no 19ํㅜ dia pós-lesão é que os valores se normalizam ( $\mathrm{L}, \mathrm{p}=0,99$; $\mathrm{L}+\mathrm{US}, \mathrm{p}=0,99$; Fig. 10). Não houve diferença entre os grupos L e L+US em nenhum momento ao longo dos 28 dias após a lesão (p>0,05; Fig. 10).

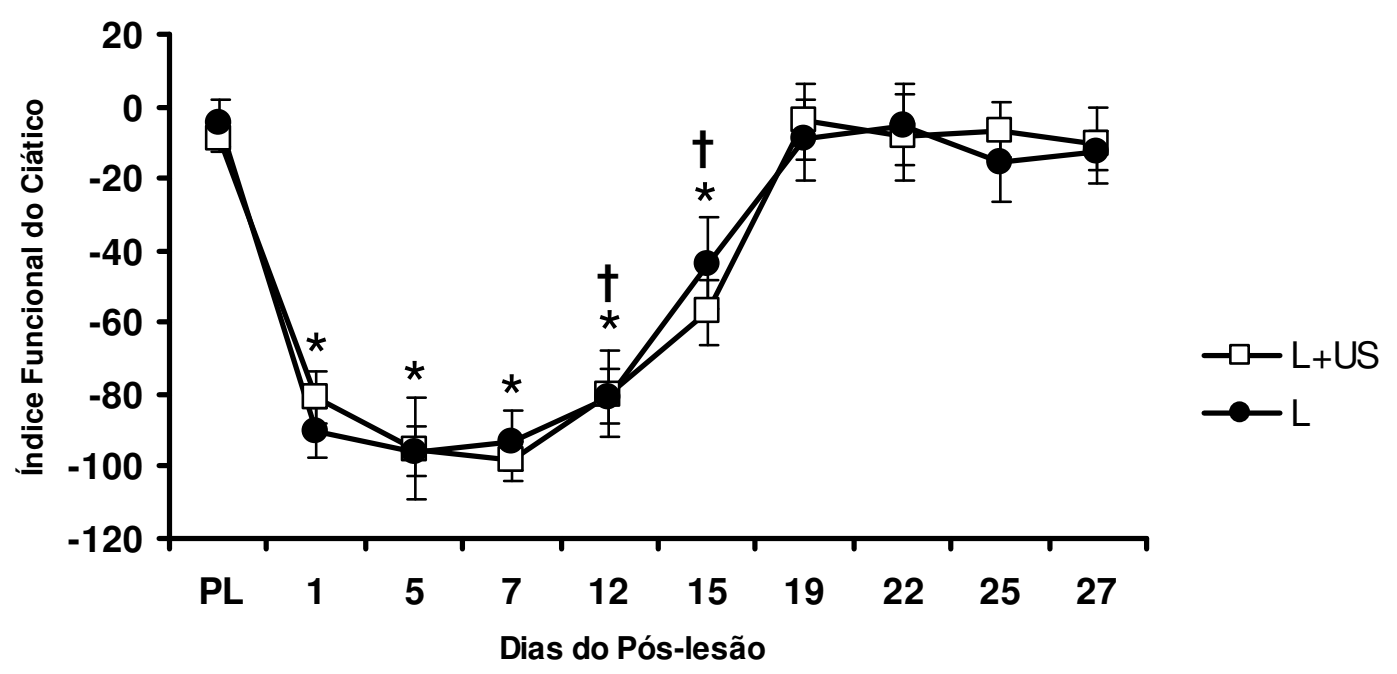

Figura 10: Índice funcional do ciático dos grupos lesado (L) e lesado tratado com ultra-som (L+US). ${ }^{*} \mathrm{p}<0,05$ : comparado aos valores normais; ${ }^{\dagger} \mathrm{p}<0,05$ : comparado a todos os momentos avaliados. Note: há uma redução dos valores do IFC no primeiro dia, persistindo na primeira semana. A recuperação da função se inicia no 12 dia e termina no 19‥ Não há diferença na função dos dois grupos avaliados (L e L+US). 


\section{DISCUSSÃO}

Atualmente existem vários estudos sobre o tratamento com ultra-som em regeneração de tecidos moles, porém, a maioria deles são controversos e não conclusivos. Dentre estes, poucos avaliaram a influência do ultra-som pulsado de baixa intensidade na lesão nervosa periférica, o que motivou a realização do presente estudo. Portanto, o objetivo estudo foi verificar a ação do ultra-som pulsado de baixa intensidade na regeneração nervosa periférica durante o processo de reparação, ou seja, até 4 semanas após a lesão. Neste estudo, o principal interesse são os parâmetros de dosimetria do ultra-som (tais como: freqüência, regime de onda, intensidade e tempo de tratamento), os quais são fatores que influenciam diretamente na recuperação da função nervosa. A escolha destes parâmetros e tempo de aplicação foram baseados em literaturas consultadas, levando em consideração a profundidade do tecido alvo (nervo) e sobre quais tecidos o ultra-som interage antes de atingir o tecido em questão. Além disso, há um interesse particular no conhecimento dos efeitos do ultra-som, uma vez que têm sido demonstrado em experiências clínicas e laboratoriais que o ultra-som pode estimular tecido de reparação e cicatrização de feridas se corretamente aplicado (DYSON, 1990).

No presente estudo, foi proposto o uso de ultra-som com o regime de onda pulsado, baixa intensidade $\left(40 \mathrm{~mW} / \mathrm{cm}^{2}\right)$, freqüência de $1,5 \mathrm{MHz}$, durante 8 minutos de aplicação em dias intercalados, por um período de 28 dias, sobre uma lesão padronizada de esmagamento do nervo ciático (BEER et al., 2001; VAREJÃO et al., 2004), com o objetivo de investigar os efeitos da terapia ultra-sônica na recuperação do mesmo. Neste estudo, o ultra-som pulsado foi escolhido para manter o mínimo de mecanismo térmico, prevalecendo o mecanismo nãotérmico. A baixa intensidade foi escolhida para estimular respostas fisiológicas à lesão (ter HAAR, 1999). 
O mecanismo não-térmico é obtido através de dois efeitos: o microfluxo e a cavitação. Estes dois efeitos são capazes de mudar a atividade celular local, alteração iônica da membrana e síntese celular que podem acelerar o processo de regeneração tecidual (DYSON, 1990). Segundo ter Haar (1999), a escolha da freqüência depende da profundidade do alvo a ser tratado; tecidos alvos mais profundos requerem baixa frequiência porque a mesma depende da atenuação ultra-sônica.

Alguns estudos encontraram resultados interessantes acerca da aplicação do ultra-som em tecidos lesados. Crisci; Ferreira (2002) concluíram que o método não-invasivo, aciona uma forte atividade das células de Schwann, mostrando a promoção da regeneração nervosa periférica, obtendo resultados favoráveis à lesão. Raso et al. (2002), aplicando ultra-som em regeneração nervosa concluiu que os possíveis efeitos são térmicos, visto por ocorrência de dilatação de vasos sangüíneos, formação de novos vasos, melhora da nutrição tecidual local, estimulação do brotamento nervoso, aumento da densidade de fibra nervosa, ativação das células de Schwann o que provocou a restauração do tubo neural, liberação de mediadores quimiotáxicos, o que estimulou a produção de axoplasma. Igualmente, Mourad et al. (2001), demonstraram que o ultra-som de baixa intensidade acelera o processo de regeneração nervosa. Além deste, Hong et al. (1988), observaram que somente as baixas intensidades podem acelerar o processo de regeneração nervosa, pois as altas intensidades podem ter efeitos desfavoráveis. Chang; Hsu (2004), utilizando enxertos biodegradáveis associados a aplicação de ultra-som, concluíram que há melhora no processo de regeneração com maior número e área de axônios mielinizados, podendo acelerar a atividade das células de Schwann para regenerar nervos. O que também foi observado por Chang et al. (2005), que o enxerto biodegradável associado ao uso de ultra-som de baixa intensidade promove uma aceleração da regeneração nervosa através das células de Schwann, diferentemente dos enxertos nãobiodegradáveis que retardam o processo de regeneração. 
Contudo, o presente estudo, não detectou estes resultados, sugerindo que a terapia com ultra-som não promoveu a recuperação do nervo ciático ao longo de 28 dias após lesão. Embora o tratamento com o ultra-som provavelmente não tenha acelerado o processo de reparação da fibra nervosa e tampouco modificado a função do nervo, não se pode descartar a possibilidade de que o ultra-som exerça algum efeito após sua lesão traumática.

Diante do exposto, observa-se que os dados são contraditórios. Este fato possivelmente ocorreu devido as diferenças nos parâmetros do ultra-som, tais como, modelo de lesão experimental e tempos de intervenção, sem nenhuma padronização, uma vez que os relatos apresentados são meramente especulativos, não esclarecendo a real ação do ultra-som no processo de regeneração nervosa. De fato, não é possível regulamentar parâmetros de utilização do ultra-som, porque os relatos não são conclusivos quanto aos seus efeitos fisiológicos e terapêuticos, ou nem quanto ao mecanismo de ação no reparo nervoso tecidual (FARMER, 1986; CURRIER et al.; 1978; apud RASO, 2002; HONG et al.; 1988; DURIGAN et al., 2006). Muito embora existam autores que sugeriram um protocolo de tratamento com intensidade de $0,25 \mathrm{~W} / \mathrm{cm}^{2}$, freqüência de $2,25 \mathrm{MHz}$, tempo de aplicação de 1 minuto, indicando que este protocolo acelera o processo de regeneração nervosa (Mourad et al., 2001), este ainda é questionável.

No presente estudo, uma das variáveis importantes e contraditórias é o momento da intervenção, ou seja, de 12 horas até o $28^{\circ}$ dia após a lesão. Este tempo coincide com a fase inicial da cicatrização tecidual (12 horas pós-lesão), que é a inflamação, estendendo-se até a fase completa da cicatrização tecidual (28 dias pós-lesão), que é conhecida como remodelamento. O ultra-som utilizado corretamente durante a fase de cicatrização tecidual, pode acelerar o processo (fase inflamatória - aguda), intensificar a síntese de colágeno conferindo mais resistência à tração do tecido (fase proliferação celular) e, finalmente, pode formar cicatriz mais forte e elástica, com propriedades mecânicas mais adequadas quando 
comparado à outra cicatriz sem aplicação do ultra-som (fase de remodelamento) (DURIGAN et al., 2006).

A freqüência e tempo de tratamento dedicado ao nervo ciático, podem ter sido um dos fatores cruciais no processo de reparação. No entanto, estudos anteriores mostram uma grande diversidade nestes dois parâmetros, variando de 1 minuto (HONG et al., 1998) até 20 minutos (CRISCI; FERREIRA, 2002)_de tempo de tratamento, sendo a freqüência de tratamento em dias consecutivos em todos os estudos prévios. No presente estudo, a freqüência de tratamento foi intercalada, rigorosamente no período vespertino e o tempo de tratamento foi de 8 minutos, diferentemente dos estudos anteriores. Este tipo de protocolo adotado pode ter influenciado na ausência do efeito positivo da terapia ultra-sônica na regeneração nervosa periférica. Sugere-se que outros estudos sejam realizados para que o protocolo e o tempo de tratamento sejam definidos ou melhor estabelecidos.

Um outro possível esclarecimento sobre a ausência de efeitos positivos na regeneração nervosa periférica pós-lesão traumática, pode estar relacionado ao modelo animal e experimental da lesão por esmagamento. O rato foi o animal escolhido por ser o modelo mais utilizado em estudos com lesão nervosa periférica, por ser de fácil manuseio, baixo custo e seu nervo ciático ser semelhante ao do homem (BRIDGE et al., 1994), o que favorece estudos de natureza morfológica (RASO, 2002). Muito embora este animal possua grande capacidade de regeneração nervosa diferentemente do ser humano. A lesão por esmagamento foi escolhida como modelo experimental por preservar parte da estrutura do nervo (BRIDGE et al., 1994) e por ser o tipo de lesão mais estudada na literatura (GIGO-BENATO et al., 2005).

Bridge et al. (1994) descobriram que a lesão por esmagamento, no modelo animal de rato, corresponde ao segundo grau de lesão descrita por Sunderland_(1978), somente em raras exceções a lesão apresentará característica de primeiro ou terceiro grau de Sunderland (1978). Yao et al. (1998) demonstraram em nervo ciático de ratos e camundongos, aplicando lesão 
por esmagamento, que a regeneração ocorre entre 2 e 4 semanas após a lesão. Varejão et al. (2004) observou que a regeneração nervosa do rato é muito rápida mesmo sem qualquer tipo de intervenção terapêutica, na quarta semana pós-lesão por esmagamento, cerca de $80 \%$ da função está restaurada. Ao contrário, Oliveira et al. (2001), descobriram que a regeneração da função nervosa por esmagamento é proporcional à carga aplicada no desencadeamento da lesão, podendo atingir lesão do tipo 4 de Sunderland (1978) e a função é restabelecida em até 60 dias. Varejão et al. (2004) ressaltam que os resultados dos diferentes estudos experimentais sobre a regeneração nervosa devem ser comparados com cautela, devido às dificuldades de reprodução padronizada de uma lesão por esmagamento do nervo ciático. Com a intenção de evitar este tipo de equívoco, neste estudo foi utilizado um instrumento específico para a indução reproduzível da lesão do nervo ciático recentemente publicada (BEER et al., 2001) e padronizada (VAREJÃO et al., 2004).

Observou-se que uma carga de 9MPa provocou, no nervo, uma lesão que se identifica com uma lesão do tipo 2 de Sunderland (1978) (VAREJÃO et al., 2004). Desta forma foi possível delinear um período curto de tempo para regeneração nervosa, o que permitiu visualizar melhor as diferenças histológicas, no grupo lesado+ultra-som. Porém, os resultados do presente estudo não detectaram estas diferenças, levando em consideração que a efetividade ultra-sônica pôde ter sido mascarada pelo rápido tempo de regeneração.

De modo geral, os estudos anteriores e os recentes utilizaram para a análise quantitativa da regeneração nervosa periférica avaliações como histologia (morfologia e morfometria), funcional e eletrofisiológico. Entretanto, para avaliar a função perdida em humanos, é relativamente fácil, mas em animais é quase impossível (RASO, 2002).

Por esta razão, foi escolhido o Índice Funcional do Ciático que é um dos métodos quantitativos mais utilizados para avaliação funcional da regeneração nervosa periférica em animais, este método foi renovado por Bain et al. (1989). Este é um método não-invasivo, 
baixo custo e de fácil aplicabilidade. Sendo assim, pode-se avaliar quantitativamente a evolução da regeneração nervosa em vários períodos do experimento sem a necessidade da eutanásia animal. Para Varejão et al. (2003), a escolha do teste funcional é de suma importância nos estudos de lesão e reparação nervosa periférica. Yao et al. (1998) inferem que o Índice Funcional do Ciático é um indicador apurado do nível de regeneração neural do ciático durante a recuperação, sendo mais importante em situações clínicas do que a eletrofisiológica ou morfometria histológica.

O Índice Funcional do Ciático proposto por Bain et al. (1989), durante o período experimental deste estudo, não demonstrou diferença significativa entre os grupos lesado e lesado+US. Vale ressaltar que a partir do décimo segundo até o décimo quinto dia a evolução da função do nervo ciático foi diferente de todos os outros dias e no décimo nono dia a evolução da função se igualou ao nervo não-lesado. O estudo realizado por Yao et al. (1998), comparou a evolução funcional do nervo ciático, lesado por esmagamento, em ratos e camundongos. Os autores relataram que em ratos até o vigésimo dia pós-lesão, os nervos recuperam, livremente, a sua função. No estudo de Raso (2002), a partir do décimo quarto dia houve uma evolução da regeneração nervosa periférica, encontraram diferença estatística entre os grupos controle e ultra-som, resultados estes distintos do presente estudo. Provavelmente, este fato se deva aos parâmetros utilizados do ultra-som, o tempo de tratamento, o modelo de lesão por esmagamento terem sido diferentes em ambos estudos.

Quando há uma lesão por esmagamento do nervo, ocorre uma diminuição da contratilidade muscular e atrofia com mudanças degenerativas na membrana pós-juncional muscular, devido à influência trófica dos nervos sobre os músculos (JAWEED et al., 1975). Para Germinario et al. (2002) durante o desenvolvimento embrionário e pós-natal a diferenciação dos tipos de fibras é controlada, principalmente, pela inervação. Portanto, a influência de fatores neurotróficos não deve ser excluída. Sendo assim, não é surpresa que a 
desnervação cause profunda mudança na propriedade músculo-esquelética. Segundo Midrio (2006), a desnervação causa mudanças músculo-esquelética tais como, atrofia, alterações miofibrilares, propriedades da membrana elétrica muscular, sensibilidade a acetilcolina e processo de ligação excitação-contração, fibrilação e déficit neurotrófico. O autor ainda sugere que existe uma influência neurotrófica do nervo sobre o músculo, porém faz-se necessários mais estudos para validar a hipótese de um controle neurotrófico das propriedades musculares. Younkin et al. (1978) sugeriram que agentes neurotróficos, com efeito de inervação sobre os músculos, podem se encontrar de três maneiras distintas: estarem presentes e serem movidos por transporte axonal do nervo; estarem presentes no músculo inervado, mas ausentes ou presentes em concentração reduzida no músculo desnervado; e serem liberados pelo nervo.

Estudos prévios apontam que a lesão nervosa periférica provoca atrofia das fibras musculares, o presente estudo está de acordo com esta observação e encontrou uma diminuição da massa muscular tanto do músculo TA quanto do músculo SOL. No que diz respeito à área de secção transversa das fibras musculares, o músculo TA lesado apresentou diminuição significativa da AST, enquanto o músculo SOL lesado não apresentou diminuição quando se compado ao grupo normal. Porém, a área de secção transversa da fibra do músculo TA tratado com ultra-som não teve diferença estatística quando se comparada ao grupo normal. Embora o objetivo principal do estudo tenha sido a influência do ultra-som sobre o nervo ciático lesado, esta diminuição da massa muscular e a manutenção da área de secção transversa levantada dos músculos TA tratado com ultra-som é relevante, haja vista que foi constatada esta diminuição de massa indicando uma atrofia por desnervação e a manutenção da área de secção transversa do músculo TA, sugerindo efeito positivo do ultra-som.

Possivelmente, o que ocorreu foi que o ultra-som pulsado de baixa intensidade na tentativa de estimular a recuperação do nervo produziu uma excitação no trânsito das 
estruturas axoplasmáticas, o que ativou os fatores neurotróficos que, por sua vez influenciaram diretamente os músculos, mais especificamente a área de secção transversa do músculo TA, provocando efeitos positivos do ultra-som sobre este músculo. Este fenômeno deve ter ocorrido, provavelmente, porque as fibras musculares tipo IIB (encontradas em maior proporção no músculo TA) apresentam maior número de miofibrilas, o que caracteriza fibras mais calibrosas e favorece inicialmente o processo de degeneração das fibras, permitindo detectar maiores diferenças quando comparadas às fibras tipo I (menor número de miofibrilas sendo, portanto, menos calibrosas) e encontradas no músculo SOL. Para Germinario et al. (2002), as fibras tipo IIB representam o fenótipo com menos demanda funcional e assim menos estimulada pelo sistema nervoso, o oposto das fibras tipo I que são continuamente recrutadas. Sendo assim, o presente estudo está de acordo com estes achados, uma vez que o grupo lesado do músculo SOL (com maior número de fibras tipo I) não mostrou perda da área de secção transversa da fibra quando comparado ao normal. Os autores ainda estudaram como as propriedades do retículo sarcoplasmático de fibras tipo IIB de músculo de contração rápida (caso do músculo TA) são alterados pela desnervação. Para tal analisaram as propriedades contráteis isométricas e eletrofisiológicas do músculo desnervado e encontraram que as fibras tipo IIB são dependentes da atividade do nervo e/ou fatores neurotróficos. Observaram também que a desnervação conduz a mudanças precoces nas propriedades da membrana e contráteis do músculo de contração rápida, no entanto as mudanças no músculo de contração lenta (caso do músculo SOL) apesar de modificar as propriedades miofibrilares e do retículo sarcoplasmático, não são evidentes em 7 dias de desnervação. Haddad et al. (1997) afirmaram ser possível que as fibras tipo IIB sejam particularmente mais sensíveis à deficiência de fatores neurotróficos do nervo, quando comparadas às fibras tipo I, o que está de acordo com os resultados deste estudo. 
Na morfologia dos músculos TA e SOL tratados com ultra-som pôde-se observar, a olhos vistos, um aumento de fibroblastos nas adjacências das células musculares quando comparado aos músculos não-tratados com o ultra-som. Rantanen et al. (1999) explicam este fenômeno, entendendo que as ondas do ultra-som geram vibração e cavitação nas interfaces dos tecidos, provoca o efeito de micromassagem. Estes são indicativos de efeitos específicos sobre as células, fibroblastos em particular, tais como, a síntese de proteína é acelerada, a permeabilidade da membrana e a concentração de cálcio são aumentadas.

O interesse particular do estudo foi observar os efeitos da terapia do ultra-som pulsado de baixa intensidade na regeneração nervosa periférica após 4 semanas à lesão do tipo axoniotmese. Durante este período de tratamento, não foram encontradas diferenças significativas tanto na avaliação morfológica quanto na avaliação funcional do nervo ciático entre os grupos lesado e lesado+ultra-som. No entanto, foi observada uma manutenção da área de secção transversa do grupo lesado+ultra-som do músculo TA quando comparado ao grupo normal, sugerindo que o ultra-som estimulou o nervo para tal manutenção. Com isso, os efeitos positivos do ultra-som sobre o nervo ciático não podem ser totalmente descartados, talvez com julgamento mais detalhado dos resultados, como, por exemplo, análise molecular, seria possível observar mudanças mais sensíveis que não foram compreendidas com as análises do presente estudo. Portanto, propõe-se que estudos futuros utilizem estes tipos de recursos, que são mais detalhados e específicos, para avaliar com precisão os tecidos envolvidos na regeneração nervosa periférica e assim, compreender as reações metabólicas do corpo à irradiação ultra-sônica, principalmente na prática clínica. Objetivando um protocolo e tempo de tratamento mais específicos e eficientes para a recuperação da regeneração nervosa. 


\section{CONCLUSÃO}

Com a realização deste estudo experimental foi possível chegar as seguintes conclusões:

- O tratamento com o ultra-som pulsado de baixa intensidade na regeneração nervosa periférica, não obteve resultados significativos quando se comparou os grupos lesado e lesado+ultra-som.

- O protocolo e o tempo de tratamento adotados para este estudo não foram suficientes para a regeneração tecidual do nervo ciático esmagado.

- Porém, não se pode descartar totalmente a influência do ultra-som sobre o nervo periférico uma vez que o músculo TA tratado manteve a área de secção transversa quando comparado ao grupo normal. 


\section{REFERÊNCIAS BIBLIOGRÁFICAS}

AZZE RJ, MATTAR, Jr. R.. Lesões dos Nervos Periféricos. In: Pardini Jr. AG, editor. Traumatismos da mão, $3^{\circ}$ ed., Rio de Janeiro, Medsi, 2000.

BAILEY, M. R.; KHOKALOVA, V. A.; SAPOZHNIKOV, O. A.; KARGL, S. G.; CRUN, L.A.. Physical mechanisms of the therapeutic effect of ultrasound (A Review). Acoustical phys. v. 49, n. 4, 2003, p. 437-4.

BAIN, J.R.; MACKINNON, S.E.; HUNTER, D.A. Functional evaluation of complete sciatic, peroneal, and posterior tibial nerve lesions in the rat. Plast. Reconstr. Surg., v. 83, 1989, p. 129-36.

BAKER, K. G.; ROBERTSON, V. J.; DUCK, F. A. A review of therapeutic ultrasound: Biophysical effects. Phys. Ther., v. 81, n. 7, 2001, p. 1351-58.

BARNETT, S, B.; ROTT, H. D.; ter HAAR, G. R.; ZISKIN, M. C.; MAEDA, K. The sensitivity of biological tissue to ultrasound. Ultrasound in Med. \& Biol., v. 23, n. 6, 1997, p. $805-12$.

BASSOLI, D. A. Avaliação dos efeitos do US pulsado de baixa intensidade na regeneração do músculo esquelético com vistas à aplicabilidade em clínica fisioterapêutica. São Carlos. 2001, p. 93. Dissertação (mestrado) - Escola de Engenharia de São Carlos. Universidade de São Paulo.

BEER, G.M., STEURER, J. e MEYER, V.E. Standardizing nerve crushes with a non-serrated clamp. J. of Rec. Microsurg. v.17, 2001, p.531-534.

BELLINGTON, L.; CARLSON, B.M. The recovery of long-term denervated rat muscles after marcaine treatment and grafting. J. Neurol., v.144, 1996, p. 147-155.

BRIDGE, P. M.; BALL, D. J.; NAKAO, Y.; BRANDT, K.; HNTER, D. A.; HERTL, T. Nerve crush injuries - A model for axonotmesis. Exp. Neurol., v.127, 1994, p. $284-290$.

CARLSON, B.M.; FAULKNER, J.A. The regeneration of skeletal muscle fibers following injury: a review. Med. Sci. Esports Exerc., v.26, 1996, p.432-9 
CHANG, C.J.; HSU, S.H. The effects of low-intensity ultrasound of peripheral nerve regeneration in poly (-lactic acid-co-glycolic acid) conduits seeded with Schwann cells. Ultrasound Med. \& Biol.,2004, p.99-108.

C.J.; HSU, S.H.; LIN, F.T.; CHANG, H. CHANG, C.S. Low-intensity-UltrasoundAccelerated Nerve Regeneration Using Cell-Seeded Poly ( ${ }^{\mathrm{D}, \mathrm{L}}$ - Lactic Acid-co-Glycolic Acid) Conduits: An In Vivo and In Vitro Study. Wiley InterSc. 2005, p.99-107.

CRISCI, A. R. Estudo experimental dos efeitos do US pulsado de baixa intensidade sobre a regeneração do nervo ciático de ratos após neurotomia, mediante avaliações morfológicas e morfométricas. São Carlos, 2001, p.73 Dissertação (mestrado) - Escola de Engenharia de São Carlos. Universidade de São Paulo.

A.R.; FERREIRA, A.L. Low-intensity pulsed ultrasound accelerates the regeneration of the sciatic nerve after neurotomy in rats. Ultrasound Med. \& Biol., v.28, n.10, 2002, p.1335-341.

COBEA. Princípios éticos na experimentação animal. Colégio Brasileiro de Experimentação Animal. Junho, 1991.

CUNHA, A.M.; PARIZZOTO, N.A.; VIDAL, B.C. The effect of therapeutic ultrasound on repair of the achilles tendon (tendon calcaneus) of the rat. Ultrasound Med. \& Biol., v.27, 2001, n.12, 1691-6.

DOAN, N.; REHER, P.; MEGHJI, S., HARRIS, M. In vitro effects of therapeutic ultrasound on cell proliferation, protein synthesis, and cytokine production by human fibroblasts, osteoblasts and monocytes. J.Oral Maxillofac Surg, v. 57, 1999, p. 409-419.

DOCKER, M. F. A review of instrumentation available for therapeutic ultrasound. Phys. Ther., v. 73, n. 4, 1987, p. 154-155.

DURIGAN, J.L.Q.; COSTA, C.N.; BORGES, H.E. Efeito do ultra-som terapêutico associado a indometacina no edema de ratos artríticos. Fisioter. Bras., v.6, n.2, 2005, p.130-5.

DURIGAN, J.L.Q.; CANCELLIERO, K.M.; REIS, M.S.; DIAS, C.N.K.; GRACIOTTO, D.R.; SILVA, C.A.; POLACOW; M.L.O. Mecanismos de interação do ultra-som terapêutico com tecidos biológicos. Fisiot. Brasil., v.7, n.2, 2006, p.142-48.

DYSON, M. Mechanism involved in therapeutic ultrasound. Phys.Ther., v.73, n. 3, 1987, p.116-20. 
M. Role of Ultrasound in Wound Healing. In: KLOTH, L.C. et al. (eds). Alternatives in Wound Management. Phyladelphia. F.A. Davis, 1990, p.259-284.

ENDO, C. Estudo do efeito do tratamento com laser num modelo experimental de lesão por esmagamento de nervo ciático de rato. Ribeirão Preto, 2002, p.133. Dissertação (Mestrado)-Escola de Engenharia de São Carlos/ Faculdade de Medicina de Ribeirão Preto, Universidade de São Paulo.

EVANS, G.R. Peripheral nerve injury: a review and approach to tissue engineered constructs. Anat. Rec. v.263, 2001, p.396-404.

GEOFFREY, R.; HARRIS, M.; JEFFREY, L.S. Managing musculoskeletal complaints with rehabilitation therapy: Summary of the Philadelphia Panel evidence-based clinical practice guidelines on musculoskeletal rehabilitation interventions. J. Fam. Pract., v.51, n.12, 2002, p.1042-46.

GERMINARIO, E.; ESPOSITO, A.; MEGIGHIAN, A.; MIDRIO, M.; BIRAL, D.; BETTO, R.; BETTO, D.D. Early changes of type $2 \mathrm{~B}$ fibers after denervation of rat EDL skeletal muscle. J. Appl. Physiol., v.92, 2002, p.2045-52.

GIGO-BENATTO, D.

GORDON,

GULATI,

ter HAAR, G. Review - Therapeutic ultrasound. Eur. J. of Ultrasound, v. 9, 1999, p. 3-9.

HAACH, L.C.A. Estudo do efeito do ultra-som pulsado de baixa intensidade e do exercício físico na manutenção de massa óssea pós-ovarectomia em modelo animal. São Carlos. 2006 p.83 Dissertação (Mestrado)-Escola de Engenharia de São Carlos-Universidade de São Paulo.

HADDAD, F.; ARNOLD, C.; ZENG, M.; BALDWIN, K. Interaction of thyroid state and denervation on skeletal myosin heavy chain expression. Muscle Nerve, v.20, 1997, p.14871496.

HNIK, P. Rate of denervation muscle atrophy. Publishing house of Czechoslovack academy of acience, 1962, p.341-371. 
HOGAN, R.D.; BURKE, K.M.; FRANKLIN, T.D. The effect of ultrasound on microvascular hemodynamics in skeletal muscle: effects during ischemia. Microvasc. Res., v.23, n.3, 1982, p.370-9.

HONG, C. Z.; LIU, H.H.; YU, J. Ultrasound Thermotherapy effect on the recovery of nerve conduction on experimental compression neuropathy. Arch. Phys. Med. Rehabil., v. 69, 1988, p. 410- 14.

ISHIDO, M.; KAMI, K.; MITSUHIKO, M. In vivo expression patterns of myoD, P21 and Rb proteins in myonclei and satellite cells of denervated rat skeletal muscle. Am. J. Physiol. Cell. Physiol., v.287, 2004, p. C 484-C 493.

JAWEED, M.M.; HERBISON, G.J.; DITUNNO, J.F. Denervation and Reinnervation of fast and slow muscle a histochemical study in rats. J. of Histochem. and Cytochem., v. 23, n.11, 1975, p. 808-27.

KOEKE, P.; PARIZOTTO, N.A.; CARRINHO, P.M.; SALATE, A.C. B. Comparative study oh the efficacy of the topical application of hydrocortisone, therapeutic ultrasound and phonophoresis on the tissue repair process in rat tendons. Ultras. In Med. \& Biol., v.31, n.3, 2005, p.345-50.

KOSTROMINOVA, T.Y.; DOW, D.E.; DENNIS, R.G.; MILLER, R.A.; FAULKNER, J.A. Comparasion of gene expression of two-month denervated, two-month stimulated- denervated and control rat skeletal muscles. Physiol. Genomics, v.22, 2005, p. 227-243.

KUREK, J.B.; AUSTIN, L.; CHEEMAS,S.S.; BARTLTT, P.F.; MURPHY,M. UPRegulation of leukaemia inhibitory factor and interleukin-6 transected sciatic nerve and muscle following denervation. Neuromusc. Disord., v.6, n.2, 1996, p.105-14.

LIEBER, R. Skeletal muscle structural, function, \& Plasticity. Lippencott Willims \& Wilkins, $2^{\circ}$ ed, Philadelphia, 2002.

LOWDON, I.M.R.; SEABER, A.V.; URBANIAK, J.R. An improved method of recording rat tracks for mesrament of the sciatic functional index of De Medinacelli. J. Neurosci. Methods, v.24, 1988, p.279-81.

LUNDBORG, G. A. 25-year perspective of peripheral nerve surgery: evolving neuroscientific concepts and clinical significance. J. Hand Surg., v.25, 2000, p.391-414. 
MARKERT, C. D.; MERRICK, M. A.; KIRBY, T. E.; DEOOR, S. T. Nonthermal ltrasound and exercise in skeletal muscle regeneration. Arch. Phys. Med. Rehabil., v. 86, 2005, p. 1301-10.

MACHADO, A. Neuroanatomia Funcional. $2^{\circ}$ ed. Atheneu, SP, 2004.

MARQUESTE, T.; DECHERCHI, P.; DOUSSET, E.; BERTHELIN, F.; JAMMES, Y. Effect of muscle electrostimulation on afferente activities from tibialis anterior muscle after nerve repair by self-anastomosis. Neurosci., v.113, n.2, 2002, p. 257-71.

MAXWELL, L. Therapeutic ultrasound: Its effects on the cellular and molecular mechanisms of inflammation and repair. Physiotherapy, v.78, n.6, 1992, p. 421-26.

MENDONÇA, C.H. BARBIERI, and MAZZER, N. Directly applied low intensity direct electric current enhances peripheral nerve regeneration in rats, J Neurosci Meth 129, 2003, p. 183-190.

MIDRIO, M. The denervated muscle: facts and hypotheses. A historical review. Eur. J. Appl. Physiol., v.98, 2006, p.1-21.

MILLESI, H. Techniques for nerve grafting. Hand Clinics, v.16, 2000, p.73-91.

MOORE, J.H.; GIECK, J. H.; SALIBA, E. N.; PERRIEN, D. H.; BALL, D. W.; McCUE, F. C. The biophysical effects of ultrasound on median nerve distal latencies. Electromyogr. Clin. Neouphysiol., v. 40, n. 3, 2000, p. $169-80$.

MOURAD, P.D.; LAZAR, D.A.; CURRA, F.P.; MOHR, B.C.; ANDRUS, K.C.; AVELINO, A.M.; McNUTT, L.D.; CRUM, L.A.; KLIOT, M. Ultrasound accelerates functional recovery after peripheral nerve damage. Neurosurg.,v.48, n.5, 2001, p.1136-140.

OLIVEIRA, E.F.; MAZZER, N.; BARBIERI, C.H.; SELLI, M. Correlation between functional index and morphometry to evaluate recovery of the rat sciatic nerve following crush injury: experimental study, J Reconstr Microsurg., v.17, n.1, 2001, p. 69-75.

RANTANEN, J.; THORSSON, O.; WOLLMER, P.; HURME, T.; KALIMO, H. Effects of therapeutic ultrasound on the regeneration of skeletal myofibers after experimental muscle injury. Am. J. Sports Med., v.27, n.1, 1999, p.54-59. 
RASO, V. V. M. Os efeitos do ultra-som terapêutico no tratamento das lesões por esmagamento do nervo ciático de ratos. Ribeirão Preto. 2002. 59 p. Dissertação (mestrado)

- Faculdade de Medicina de Ribeirão Preto. Universidade de São Paulo.

, V.V.M.; BARBIERI, C.H.; MAZZER, N.; FAZAN, V.P.S. Can therapeutic ultrasound influence the regenation of peripheral nerves? J. of Neurosci. Methods, v. 142, 2005,p. 185192.

V. V. M.; BARBIERI, C. H.; MAZZER, N.; FAZAN, V. P. S. Os efeitos do US terapêutico nas lesões por esmagamento do nervo ciático de ratos. Análise funcional da marcha. Rev. Bras. Fisioter., v. 10, n. 1, 2006, p. 113 - 119.

ROLLO, J.M.D.A. Processo de tratamento de Osteoporose não Invasivo e sem Regime Medicamentoso. Patente: 0402649-7, 2004.

SEDDON, H. Three types of nerve injury. Brain, v.66, 1943, p.227-288.

SUNDERLAND, S. Nerves and nerve injuries. Churchill Livingstone, New York, 1978.

S. Nerve and Nerve Injure, second ed. Churchill Livingstone, London, 1985.

VAREJÃO, A.S.P. Recuperação Funcional num Modelo Experimental. Universidade de Trás-os-Montes e Alto Douro,Vila Real, 2003, p.261-270.

A.S.; CABRITA, A.M., MEEK, M.F.; BULAZ-CRUZ, J.; MELO-PINTO, P.; RAIMONDO, S.; GEUNA, S.; GIACOBINI-ROBECCHI, M.G. Functional and Morphological Assesment of a Standardized Rat Sciatic Nerve Crush Injury with a NonSerrated Clamp. J. Neurotrauma, v.21, 2004, p. 1652-1670.

YAO, M.; INSERRA, M.M.; DUH, M.J.; TERRIS, D.J. A longitudinal, functional study of peripheral nerve recovery in the mouse. Laryngoscope, v.108, 1998, p. 1141-1145.

YOUNKIN, S.G.; BRETT, R.S.; DAVEY, B.; YOUNKIN, L.H. Substances moved by axonal transport and released by nerve stimulation have an inervation-like effect on muscle. Science, v.200, 1978, p.1292-1295. 
ANEXO I - Aprovação do Comitê de Ética em Experimentação Animal da UFSCar

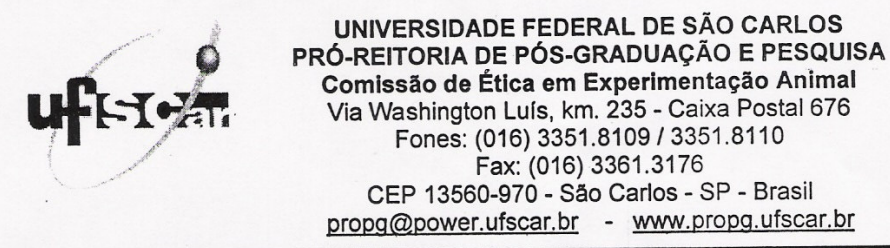

\section{Parecer CEEA 005/2006}

A Comissão de Ética em Experimentação Animal da Universidade Federal de São Carlos - CCEA/UFSCar - na sua 6a. Reunião, ocorrida em 25/04/2006, APROVOU o trabalho intitulado Efeito do ultra-som pulsado de baixa intensidade em nervo periférico axoniotimizados de ratos da raça Wistar, dos autores Daiana Sganzella e Prof. Dr. João M. D. A. Rollo, procedente da USP/PPGBioengenharia. Protocolo CCEA nº 004/2006.

São Carlos, 26 de abril de 2006.

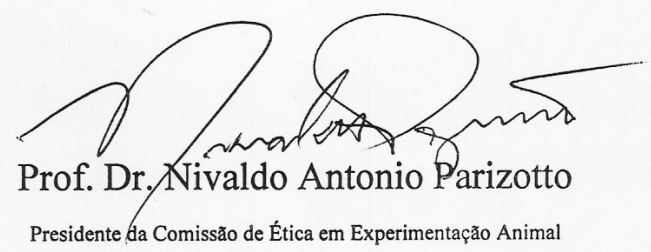

Presidente da Comissão de Ética em Experimentação Animal

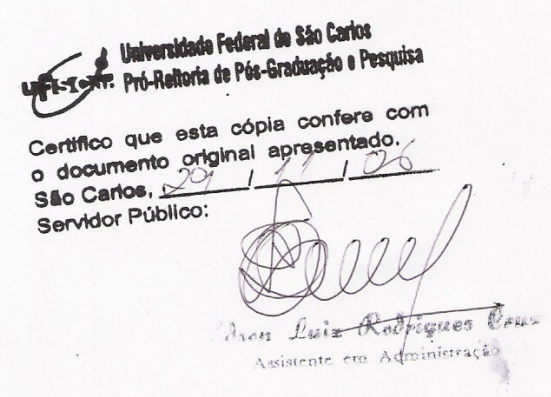


ANEXO II - Escala de Sunderland (retirado da Revista de Neurociência, v.3, n²)

a) Lesões de grau 1: é a lesão que corresponde a neuropraxia. Consiste em um bloqueio da condução nervosa causada por pressão intraneural elevada. O que ocorre é que o nervo não conduz impulsos ao nível do local da lesão, apenas existirá condução no segmento distal. A resposta a eletromiografia evocada será normal. Não existem mudanças morfológicas. Se houver descompressão no local da lesão, a recuperação clínica ocorre imediatamente, chegando a 3 ou 4 semanas após a lesão, porém não deixa seqüelas.

b) Lesões de grau 2: esta lesão corresponde a axonotmese. Se não houver a descompressão, haverá a morte do segmento distal do axônio. Acredita-se que o mecanismo desse tipo de lesão é a obstrução venosa causada pela pressão intraneural elevada que produz um maior acúmulo de axoplasma acompanhada pela ingurgitação proximal e distal e a interrupção final do fluxo de nutrientes para o nervo através das arteríolas comprimidas. A resposta da eletromiografia evocada é aproximadamente $25 \%$ do normal. Se a compressão ceder, a recuperação é completa e sem seqüelas, já que os tubos endoneurais guiam perfeitamente o crescimento do axônio a partir do ramo distal. A recuperação clínica é mais prolongada, dependendo da velocidade do crescimento axônico.Usualmente começa em 1 ou 2 meses. Em pacientes com paralisia de Bell, herpes zoster cefálica, e otite média aguda, as lesões do nervo facial são de primeiro ou segundo grau e somente algumas vezes de terceiro grau. O mesmo pode ocorrer quando a paralisia é devido a um tumor ou uma fratura, onde geralmente o nervo é mais comprimido que seccionado.

c) Lesões de grau 3: neste tipo de lesão a pressão intraneural é intensa e prolongada, não causa somente a perda do axônio mas também dos tubos endoneurais. A resposta a eletromiografia evocada será de 0 a $10 \%$ do normal. Os prolongamentos originados a partir do ramo distal seccionado penetram nos tubos endoneurais distais incorretos e se misturam, portanto, a inervação dos músculos faciais acontecerá de forma desordenada. O resultado será uma paralisia facial desordenada cuja recuperação inicia-se em dois a quatro meses e os movimentos serão acompanhados de sincinesias, por exemplo, movimento da boca ao tentar fechar os olhos.

d) Lesões de grau 4: consiste na transecção parcial do nervo. Resulta na interrupção do perineuro que reveste os fascículos nervosos. A formação de cicatriz fibrosa no ponto da transecção bloqueia a regeneração do nervo. Não há resposta a eletromiografia evocada. A recuperação clínica começa entra 4 a 18 meses, nunca é completa e é acompanhada de sincinesias.

e) Lesões de grau 5: consiste na transecção total do nervo com interrupção do epineuro. A formação da cicatriz fibrosa no ponto da transecção bloqueia a regeneração do nervo. Não há resposta a eletromiografia evocada. Nunca haverá recuperação espontânea. 
